\title{
Evaluation of exposures and respiratory health at a coffee roasting and packaging facility and two off-site retail cafés
}

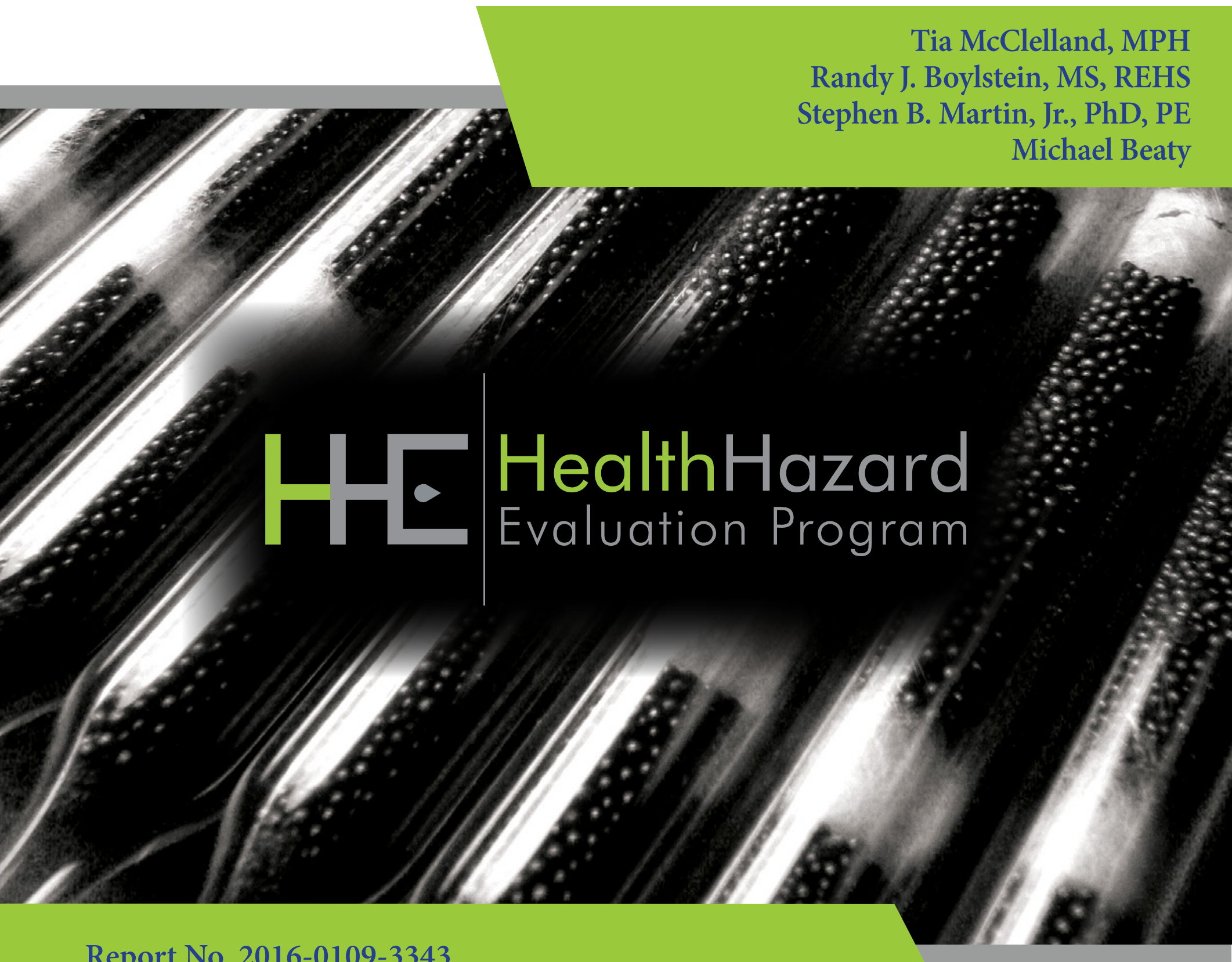

March 2019

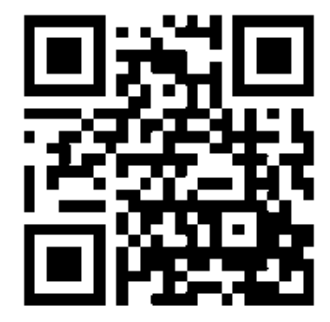

U.S. Department of Health and Human Services Centers for Disease Control and Prevention

National Institute for Occupational Safety and Health

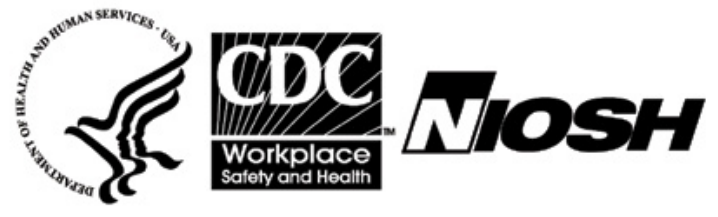




\section{Contents}

Highlights................................................... i

Abbreviations .........................................v

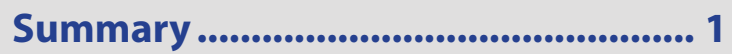

Introduction .......................................... 2

Background............................................ 2

Process Description ............................... 6

Methods ............................................. 7

Results .......................................... 12

Discussion .......................................... 17

Conclusions.......................................... 23

Recommendations.............................. 24

Appendix A: Tables .............................. 29

References........................................... 36

Acknowledgements............................. 46

The employer is required to post a copy of this report for 30 days at or near the workplace(s) of affected employees. The employer must take steps to ensure that the posted report is not altered, defaced, or covered by other material.

The cover photo is a close-up image of sorbent tubes, which are used by the HHE Program to measure airborne exposures. This photo is an artistic representation that may not be related to this Health Hazard Evaluation. 


\section{Highlights of this Evaluation}

The Health Hazard Evaluation Program of the National Institute for Occupational Safety and Health received a request from the owner of a coffee roasting and packaging facility and offsite retail cafés regarding concerns about exposures to and health effects from diacetyl and 2,3-pentanedione during coffee roasting, coffee grinding, and café tasks.

\section{What We Did}

- We visited the roastery production space and two off-site retail cafés on May 15-18, 2017.

- We collected full-shift (hours), task (minutes), and instantaneous (seconds) air samples to measure concentrations of the alphadiketones diacetyl, 2,3-pentanedione, and 2,3-hexanedione over multiple days during the visit.

- We measured real-time air levels of carbon monoxide and carbon dioxide.

- We assessed the ventilation system at each location.

- We administered a health questionnaire to employees and performed breathing tests; we mailed employees their individual breathing test results.

\section{What We Found}

- On full-shift sampling, some employees (baristas) were exposed to diacetyl and 2,3-pentanedione at concentrations above the recommended exposure limits of 5 parts per billion and 9.3 parts per billion respectively. The highest measured concentrations of 13.9 parts per billion for diacetyl and 15.6 parts per billion for 2,3-pentanedione were measured on a café employee while grinding roasted coffee beans in the basement of the downtown café.

- Levels of diacetyl in the air during short-term sampling were higher for tasks involving grinding roasted beans (maximum 124.5 parts per billion).
We evaluated respiratory health and airborne exposures to alpha-diketones (diacetyl, 2,3-pentanedione, and 2,3-hexanedione), other volatile organic compounds, carbon monoxide, and carbon dioxide among employees at a coffee roasting and packaging facility and two retail cafés. Diacetyl and 2,3-pentanedione were detected in a majority of full-shift personal breathing zone air samples, with a maximum concentration of diacetyl of 13.9 parts per billion and of 2,3-pentanedione of 15.6 parts per billion. Five of the fullshift samples, captured from baristas, exceeded the NIOSH recommended exposure limit for diacetyl of 5 parts per billion. In addition, two 15-minute short-term exposure samples collected on an employee grinding roasted coffee beans exceeded the NIOSH shortterm exposure limit for diacetyl. Two 15-minute samples collected on an employee grinding roasted coffee beans was above the short-term exposure limit for 2,3-pentanedione. Air levels of carbon monoxide at each location were below the exposure limits. Nose, eye, and sinus symptoms were the most commonly reported symptoms. Wheezing was the most common lower respiratory symptom reported. All spirometry tests were interpreted as normal. One participant had high exhaled nitric oxide, a marker of allergic airways inflammation. We recommend introducing prescribed amounts of fresh, outdoor air into the café spaces, operating the ventilation system in the roastery production space continuously during the work shift; relocating the grinders in the basement of the downtown café; installing local exhaust ventilation; implementing administrative controls such as modification of work practices; and training employees about work-place hazards. We also recommend instituting a medical monitoring program. 
- Carbon monoxide levels were low at all locations.

- The ventilation at the roastery was effective at controlling airborne concentrations of alpha-diketones below the recommended exposure limits for diacetyl and 2,3-pentanedione; ventilation at the cafés was ineffective at controlling exposures to acceptable levels.

- Nose, eye, and sinus symptoms were the most commonly reported symptoms. One employee reported symptoms that were caused or aggravated by dust.

- Wheezing or whistling in the chest was the most commonly reported lower respiratory symptom.

- All spirometry tests were interpreted as normal.

- One of nine participants had high exhaled nitric oxide, a marker of allergic airways inflammation.

\section{What the Employer Can Do}

- Ensure employees understand potential hazards (e.g., diacetyl, 2,3-pentanedione, carbon monoxide, carbon dioxide, green and roasted coffee dust) in the workplace and how to protect themselves.

- Install local exhaust ventilation at grinder locations to capture diacetyl, 2,3-pentanedione, and carbon monoxide emissions from ground coffee.

- Relocate the cold brew grinder in the basement of the downtown café closer to an outside wall and install either an exhaust fan or ducted local exhaust ventilation system to exhaust contaminants generated during grinding directly outdoors.

- Operate the ventilation system in the roastery production space continuously during the work shift.

- Work with a ventilation expert to bring in appropriate levels of outdoor air to meet ASHARAE ventilation guidelines for cafés.

- Provide an alternative method to hand-blending roasted coffee beans that minimizes employee contact with roasted beans during blending.

- Eliminate the use of dry sweeping as much as possible during cleaning; particularly in areas where green beans are stored. Instead, use a vacuum system with a highefficiency particle air filter and wet methods whenever possible.

- Conduct follow-up air sampling to verify that the modifications have been effective in reducing exposures to below the recommended exposure limits. If air levels in the cafés are not below recommended levels, work with a ventilation engineer to install local exhaust associated with café grinder tasks.

- Make N95 disposable filtering-facepiece respirators available for voluntary use for protection against coffee dust exposure, such as when emptying burlap bags of green beans, cleaning the roaster, or cleaning the green bean storage area. 
- Encourage employees to report new or ongoing respiratory symptoms to their personal healthcare providers and to a designated individual at the workplace.

- Institute a medical monitoring program for employees who work in the production area.

\section{What Employees Can Do}

- Operate the ventilation system at all times in the roastery production space during the work shift.

- Use any local exhaust ventilation as instructed by your employer when it is installed.

- Follow your employer's instructions for an alternative method to hand-blending roasted coffee beans.

- Some employees may wish to use N95 disposable filtering-facepiece respirators when emptying burlap bags of green beans, cleaning the roaster, or cleaning the green bean storage area.

- Report new, persistent, or worsening respiratory symptoms to your personal healthcare providers and a designated individual at your workplace.

- Participate in any personal air sampling offered by your employer.

- Participate in your employer's medical monitoring program as instructed by your employer. 
This page left intentionally blank 


\section{Abbreviations}

$\begin{array}{ll}\text { ACGIH } & \text { American Conference of Governmental Industrial Hygienists } \\ \text { APF } & \text { Assigned protection factor } \\ \text { cfm } & \text { Cubic feet per minute } \\ \text { CFR } & \text { Code of Federal Regulations } \\ \text { CO } & \text { Carbon monoxide } \\ \text { CO }_{2} & \text { Carbon dioxide } \\ \text { COPD } & \text { Chronic obstructive pulmonary disease } \\ \text { DR5-R20 } & \text { The difference between resistance at } 5 \text { and } 20 \text { Hertz } \\ \text { FEV } & \text { 1-second forced expiratory volume } \\ \text { Fres } & \text { Resonant frequency } \\ \text { FVC } & \text { Forced vital capacity } \\ \text { HVAC } & \text { Heating, ventilation, and air-conditioning } \\ \text { IDLH } & \text { Immediately dangerous to life or health } \\ \text { LOD } & \text { Limit of detection } \\ \mu \mathrm{g} & \text { Microgram } \\ \text { NHANES } & \text { National Health and Nutrition Examination Survey } \\ \text { NIOSH } & \text { National Institute for Occupational Safety and Health } \\ \text { OEL } & \text { Occupational exposure limit } \\ \text { OSHA } & \text { Occupational Safety and Health Administration } \\ \text { PEL } & \text { Permissible exposure limit } \\ \text { ppb } & \text { Parts per billion } \\ \text { ppm } & \text { Parts per million } \\ \text { R5 } & \text { Resistance at } 5 \text { Hertz } \\ \text { R20 } & \text { Resistance at } 20 \text { Hertz } \\ \text { REL } & \text { Recommended exposure limit } \\ \text { RH } & \text { Relative humidity } \\ \text { SMR } & \text { Standardized morbidity ratio } \\ \text { STEL } & \text { Short-term exposure limit } \\ \text { TLV }{ }^{2} & \text { Threshold limit value } \\ \text { TVOC } & \text { Total volatile organic compound } \\ \text { TWA } & \text { Time-weighted average } \\ \text { VOC } & \text { Volatile organic compound } \\ \text { X5 } & \text { Reactance at } 5 \text { Hertz } \\ & \end{array}$




\section{Summary}

In March 2016, the National Institute for Occupational Safety and Health's Health Hazard Evaluation Program received a request from the owner of a coffee roasting and packaging facility and off-site retail cafés with 15 employees regarding concerns about exposures to and health effects from diacetyl and 2,3-pentanedione during coffee roasting, coffee grinding, and café tasks. In May 2017, we conducted the medical survey, industrial hygiene survey, and ventilation assessment at the roastery production space and two off-site retail cafés. The industrial hygiene survey consisted of collecting personal breathing zone and area air samples for alpha-diketones (i.e., diacetyl, 2,3-pentanedione, and 2,3-hexanedione). We used continuous monitoring instruments to measure total volatile organic compounds, carbon monoxide, carbon dioxide, temperature, and relative humidity in specific areas and during tasks. We also conducted a ventilation assessment in both cafés and the roastery production space location. The medical survey consisted of a health questionnaire and breathing tests. An interim letter reporting industrial hygiene results and recommendations was sent to the company following our visit.

Most time-weighted average air concentrations of diacetyl and 2,3-pentanedione were below the NIOSH recommended exposure limits. Five of the 13 full-shift samples collected during the survey exceeded the NIOSH recommended exposure limit for diacetyl of 5 parts per billion, with a maximum concentration of 13.9 parts per billion. We identified jobs where some work tasks resulted in relatively higher air concentrations of diacetyl than other tasks. Specifically, grinding roasted coffee beans was associated with higher diacetyl levels.

Overall, the most commonly reported symptoms were associated with mucous membranes, specifically the nose, eyes, and sinuses. Most employees reported that they did not feel that their symptoms were caused or aggravated by work-related exposures. Wheezing or whistling in the chest was the most commonly reported lower respiratory symptom, $33 \%$ of employees reported experiencing this symptom in the last 12 months. All administered spirometry tests $(\mathrm{n}=9)$ were normal. One of nine participants had high exhaled nitric oxide, a marker of allergic airways inflammation, and three of nine participants had airway obstructions. We recommend moving the cold brew grinders in the basement of the downtown café closer to an outside wall and installing an exhaust fan or ducted local exhaust ventilation system to exhaust contaminants generated during grinding directly outdoors. We also recommend introducing prescribed amounts of fresh, outdoor air to the café spaces to help further reduce airborne concentrations. Further, we recommended operating the ventilation system in the roastery production space continuously during roastery operating hours, training employees about workplace hazards, and establishing a medical monitoring program to identify any employees who may be developing work-related lung disease (e.g., asthma, obliterative bronchiolitis) and to help management prioritize interventions to prevent occupational lung disease. 


\section{Introduction}

In March 2016, the National Institute for Occupational Safety and Health (NIOSH) received a management request for a health hazard evaluation at a coffee roasting and packaging facility and two off-site retail café locations regarding potential employee exposure to diacetyl and 2,3-pentanedione during coffee processing and café tasks. In May 2017, we conducted medical and industrial hygiene surveys and a ventilation assessment in all three locations; the roastery production space, the downtown café, and the uptown café. We collected area and personal breathing zone air samples for volatile organic compounds (VOCs), including diacetyl, 2,3-pentanedione, and 2,3-hexanedione. We monitored carbon monoxide (CO), carbon dioxide $\left(\mathrm{CO}_{2}\right)$, and total VOCs. After the visit, we provided two interim reports with recommendations.

\section{Background}

\section{Diacetyl and 2,3-Pentanedione}

Diacetyl (2,3-butanedione) and 2,3-pentanedione (acetyl propionyl) are VOCs known as alpha-diketones that are added as ingredients in food flavorings used in some food products such as microwave popcorn, bakery mixes, and flavored coffee [Day et al. 2011; Kanwal et al. 2006; Bailey et al. 2015]. Diacetyl, 2,3-pentanedione, other VOCs, and gases such as CO and $\mathrm{CO}_{2}$ are naturally produced and released during the coffee roasting process [Duling et al. 2016; Raffel and Thompson 2013; Daglia et al. 2007; Nishimura et al. 2003; Newton 2002]. Grinding roasted coffee beans produces a greater surface area for off-gassing (sometimes called degassing) of these compounds [Akiyama et al. 2003]. Often, coffee roasting facilities package newly roasted coffee in permeable bags or in bags fitted with one-way valves to allow the coffee to off-gas after it is packaged. Sometimes, newly roasted coffee is placed in bins or containers and allowed to off-gas before packaging.

NIOSH has recommended exposure limits (RELs) for diacetyl and 2,3-pentanedione in workplace air (Table 1) [NIOSH 2016]. The NIOSH objective in establishing RELs for diacetyl and 2,3-pentanedione is to reduce the risk of respiratory impairment (decreased lung function) and the severe irreversible lung disease obliterative bronchiolitis associated with occupational exposure to these chemicals. The NIOSH RELs are intended to protect workers exposed to diacetyl or 2,3-pentanedione for a 45-year working lifetime. The REL for diacetyl is based on a quantitative risk assessment which necessarily contains assumptions and some uncertainty. Analytical limitations current at the time were taken into consideration in setting the REL for 2,3-pentanedione. The RELs should be used as a guideline to indicate when steps should be taken to reduce exposures in the workplace.

These exposure limits and the accompanying recommendations for control of exposures were derived from a risk assessment of flavoring-exposed workers. At an exposure equal to the diacetyl REL, the risk of adverse health effects is low. NIOSH estimated that about 1 in 1,000 workers exposed to diacetyl levels of 5 parts per billion (ppb) as a time-weighted average (TWA) for 8 hours a day, 40 hours a week for a 45 -year working lifetime would 
develop reduced lung function (defined as forced expiratory volume in one second $\left[\mathrm{FEV}_{1}\right]$ below the lower limit of normal) as a result of that exposure. NIOSH predicted that around 1 in 10,000 workers exposed to diacetyl at 5 ppb for a 45 -year working lifetime would develop more severe lung function reduction $\left(\mathrm{FEV}_{1}\right.$ below $60 \%$ predicted, defined as least moderately severe by the American Thoracic Society [Pellegrino et al. 2005]). Workers exposed for less time would be at lower risk for adverse lung effects.

\section{2,3-Hexanedione}

2,3-Hexanedione is also an alpha-diketone that is sometimes used as a substitute for diacetyl and is produced naturally during coffee roasting. In a study using animals, there was some evidence that 2,3-hexanedione might also damage the lungs, but it appeared to be less toxic than diacetyl and 2,3-pentanedione [Morgan et al. 2016]. There are no established occupational exposure limits for 2,3-hexanedione.

\section{Carbon Monoxide and Carbon Dioxide}

$\mathrm{CO}$ and $\mathrm{CO}_{2}$ are gases produced by combustion. They are also produced as a result of reactions that take place during coffee roasting. These gases are released during and after roasting and grinding by a process called off-gassing [Anderson et al. 2003; Hawley et al. 2017]. High exposures to $\mathrm{CO}$ and $\mathrm{CO}_{2}$ can cause headache, dizziness, fatigue, nausea, confusion, rapid breathing, impaired consciousness, coma, and death [Newton 2002; Nishimura et al. 2003; Langford 2005; CDC 2013a; Raffel and Thompson 2013; Rose et al. 2017]. Occupational exposure limits for $\mathrm{CO}$ and $\mathrm{CO}_{2}$ are listed in Table 1.

\section{Exposure Limits}

We utilize mandatory (legally enforceable) and recommended occupational exposure limits (OELs) when evaluating workplace hazards. OELs have been developed by federal agencies and safety and health organizations to prevent adverse health effects from workplace exposures.

\section{Occupational Safety and Health Administration (OSHA) (Mandatory)}

The U.S. Department of Labor's OSHA permissible exposure limits (PELs) are legal limits that are enforceable in workplaces covered under the Occupational Safety and Health Act. OSHA PELs represent the legal maximum for a TWA exposure to a physical or chemical agent over a work shift [OSHA 2018]. OSHA short-term exposure limits (STELs) are the legal maximum average exposure for a 15-minute time period. Some chemicals also have an OSHA ceiling value which represent levels that must not be exceeded at any time. Currently, there are no PELs for diacetyl, 2,3-pentanedione, or 2,3-hexanedione. For substances for which an OSHA PEL has not been issued, violation of the OSHA General Duty Clause can be considered using available occupational exposure references and recommendations [OSHA 1993; OSHA 2003], such as the American Conference of Governmental Industrial Hygienists (ACGIH $\left.{ }^{\circledR}\right)$ Threshold Limit Values $\left(\right.$ TLVs $\left.^{\circledR}\right)$ and NIOSH RELs.

American Conference of Governmental Industrial Hygienists (ACGIH) (Recommendations) ACGIH is a professional, not-for-profit scientific association that reviews existing published, peer-reviewed scientific literature and publishes recommendations for levels of substances 
in air based on an 8-hour workday and 40-hour workweek. These recommendations are called threshold limit values $\left(\mathrm{TLVs}^{\circledR}\right.$ ) [ACGIH 2018a]. ACGIH TLVs are not standards; they are health-based guidelines derived from scientific and toxicological information. ACGIH provides TLV-TWA guidelines that are levels that should not be exceeded during any 8-hour workday of a 40-hour workweek. ACGIH also provides TLV-STEL guidelines which are 15-minute exposure levels that should not be exceeded during a workday. Exposures above the TLV-TWA but less than the TLV-STEL should be (1) less than 15 minutes, (2) occur no more than four times a day, and (3) be at least 60 minutes between exposures [ACGIH 2018a]. Additionally, ACGIH provides TLV-Ceiling values which are levels that should not be exceeded at any time during a work shift. The ACGIH TLV-TWA for diacetyl is 10 ppb. The TLV-STEL for diacetyl is $20 \mathrm{ppb}$. Currently, there is no TLV-TWA or TLV-STEL for 2,3-pentanedione. ACGIH has placed 2,3-pentanedione on the 2017 list of Chemical Substances and Other Issues Under Study [ACGIH 2018b].

National Institute for Occupational Safety and Health (NIOSH) (Recommendations) NIOSH provides RELs as TWA concentrations that should not be exceeded over an 8 or 10-hour work shift, during a 40-hour workweek [NIOSH 2010]. RELs are intended to be protective over a 45-year working lifetime. NIOSH also provides STELs which are 15-minute TWA exposures that should not be exceeded at any time during a workday [NIOSH 2010]. Some chemicals have ceiling values which are concentrations that should not be exceeded at any time [NIOSH 2010].

For some chemicals, NIOSH has established an Immediately Dangerous to Life or Health (IDLH) value. An IDLH value is a concentration of an air contaminant that can cause death or immediate or delayed permanent adverse health effects, or prevent escape from such an environment. Currently, NIOSH has RELs and STELs for diacetyl and 2,3-pentanedione. NIOSH does not have a REL or a STEL for 2,3-hexanedione. NIOSH does not have ceiling limits or IDLH values for diacetyl, 2,3-pentanedione, or 2,3-hexanedione.

For diacetyl and 2,3-pentanedione, the NIOSH RELs are $5.0 \mathrm{ppb}$ and $9.3 \mathrm{ppb}$, respectively, as a TWA for up to an 8-hour workday during a 40-hour workweek (Table 1). The NIOSH STELs are $25 \mathrm{ppb}$ for diacetyl and $31 \mathrm{ppb}$ for 2,3-pentanedione [NIOSH 2016]. The NIOSH exposure limits do not differentiate between natural and synthetic chemical origin of diacetyl or 2,3-pentanedione. Although the NIOSH exposure limit for 2,3-pentanedione is above that of diacetyl, 2,3-pentanedione has been shown to be as hazardous as diacetyl [Hubbs et al. 2012; Morgan et al. 2012]. The NIOSH REL is higher for 2,3-pentanedione than for diacetyl largely because analytic measures were not available in a validated OSHA method to detect 2,3-pentanedione at lower levels. The hazard potential probably increases when these chemicals occur in combination with each other; having exposure to chemicals with the same functional alpha-diketone group and effect on the same system or organ (e.g., lungs) can result in additive effects [ACGIH 2018a]. In addition to the REL, NIOSH also recommends an action level for diacetyl of $2.6 \mathrm{ppb}$ to be used with exposure monitoring in an effort to ensure employee exposures are routinely below the diacetyl REL. When exposures exceed the action level, employers should take corrective action (i.e., determine the source of exposure, identify methods for controlling exposure) to ensure that exposures are maintained 
below the NIOSH REL for diacetyl [NIOSH 2016].

Table 1. Personal exposure limits for compounds sampled for during the NIOSH surveys, May 2017.

\begin{tabular}{|l|c|c|c|c|c|c|}
\hline \multirow{2}{*}{ Compound } & OSHA* & \multicolumn{2}{|c|}{ ACGIH } & \multicolumn{3}{c|}{ NIOSH } \\
\cline { 2 - 7 } & PEL & TLV & STEL & REL & STEL & IDLH \\
\hline Diacetyl & - & $10 \mathrm{ppb}$ & $20 \mathrm{ppb}$ & $5.0 \mathrm{ppb} \dagger$ & $25 \mathrm{ppb}$ & - \\
\hline 2,3-Pentanedione & - & - & - & $9.3 \mathrm{ppb} \dagger$ & $31 \mathrm{ppb}$ & - \\
\hline 2,3-Hexanedione & - & - & - & - & - & - \\
\hline Carbon dioxide & $5,000 \mathrm{ppm}$ & $5,000 \mathrm{ppm}$ & $30,000 \mathrm{ppm}$ & $5,000 \mathrm{ppm}$ & $30,000 \mathrm{ppm}$ & $40,000 \mathrm{ppm}$ \\
\hline $\begin{array}{l}\text { Carbon } \\
\text { monoxide } \S\end{array}$ & $50 \mathrm{ppm}$ & $25 \mathrm{ppm}$ & - & $35 \mathrm{ppm}$ & $\begin{array}{c}200 \mathrm{ppm} \\
\text { (ceiling limit) }\end{array}$ & $1,200 \mathrm{ppm}$ \\
\hline
\end{tabular}

Note: OSHA=Occupational Safety and Health Administration; ACGIH=American Conference of Governmental Industrial Hygienists; NIOSH=National Institute for Occupational Safety and Health; PEL=permissible exposure limit; $S T E L=$ short-term exposure limit; $T L V=$ threshold limit value; $R E L=$ recommended exposure limit; IDLH=immediately dangerous to life or health; $p p b=$ parts per billion; ppm=parts per million; "-"=no exposure limit available.

*There are no OSHA STELs for the compounds in the table.

$\dagger$ The NIOSH RELs for diacetyl and 2,3-pentanedione are time-weighted averages for up to an 8-hour day during a 40-hour workweek.

§OSHA and NIOSH limits are designed for occupational exposure measurements in manufacturing and other trades that have potential sources of carbon dioxide or carbon monoxide (e.g., coffee roasting, welding, vehicle exhaust, diesel engine exhaust). Typical levels of carbon monoxide in offices are 0-5 ppm. In office settings, carbon dioxide generally should not be greater than $700 \mathrm{ppm}$ above outdoor carbon dioxide levels; this typically corresponds to indoor concentrations below $1200 \mathrm{ppm}$.

qThis is the NIOSH ceiling exposure limit for carbon monoxide. A ceiling concentration should not be exceeded at any time.

\section{Obliterative Bronchiolitis}

Obliterative bronchiolitis is a serious, often disabling, lung disease that involves scarring of the small airways (i.e., bronchioles). Symptoms of this disease can include cough, shortness of breath on exertion, or wheeze, that do not typically improve away from work [NIOSH 2012]. Occupational obliterative bronchiolitis has been identified in flavoring manufacturing workers and microwave popcorn workers who worked with flavoring chemicals or butter flavorings [Kreiss 2013; Kim et al. 2010; Kanwal et al. 2006]. Obliterative bronchiolitis has also been identified among employees at a coffee roasting and packaging facility that produced unflavored and flavored coffee [CDC 2013b]. A NIOSH health hazard evaluation at that facility found diacetyl and 2,3-pentanedione concentrations in the air that were elevated (range: $4.3 \mathrm{ppb}$ to 166 ppb diacetyl; <5.2 ppb to $199 \mathrm{ppb}$ 2,3-pentanedione) and identified three sources: 1) flavoring chemicals added to roasted coffee beans in the flavoring area; 2) grinding unflavored roasted coffee beans and packaging unflavored ground and whole bean roasted coffee in a distinct area of the facility, and 3) storing roasted coffee in hoppers for off-gassing, on a mezzanine above the grinding/packaging process [Duling et al. 2016]. At the time of the previous health hazard evaluation, employees had excess shortness of breath and obstruction on spirometry, both consistent with undiagnosed lung disease. Respiratory illness was associated with exposure and not limited to the flavoring areas [Bailey et al. 2015]. However, all employees who were diagnosed with obliterative bronchiolitis had worked in the flavoring area. To date, no cases of obliterative bronchiolitis have been reported among employees at coffee roasting and packaging 
facilities that produce only unflavored coffee.

\section{Work-related Asthma}

Work-related asthma refers to asthma that is brought on by ("occupational asthma") or made worse by ("work-exacerbated asthma" or "work-aggravated asthma") workplace exposures [Tarlo 2016; Tarlo and Lemiere 2014; OSHA 2014; Henneberger et al. 2011; NIOSH 2017 ]. It includes asthma attributable to sensitizers, which cause disease through immune (allergic) mechanisms, and asthma attributable to irritants, which cause disease through non-immune mechanisms. Symptoms of work-related asthma include episodic shortness of breath, cough, wheeze, and chest tightness. The symptoms can begin early in a work shift, towards the end of a shift, or hours after a shift. They generally, but do not always, improve or remit during periods away from work, such as on weekends or holidays.

Green and roasted coffee dust and castor beans (from cross-contamination of bags used to transport coffee) are known risk factors for occupational asthma [Figley and Rawling 1950; Karr et al. 1978; Zuskin et al. 1979, 1985; Thomas et al. 1991]. Persons who become sensitized (develop an immune reaction) to coffee dust can subsequently react to relatively low concentrations in the air. Others can experience irritant-type symptoms from exposure to coffee dust [Oldenburg et al. 2009].

\section{Process Description}

At the time of the NIOSH survey, the company consisted of four locations: a roastery production space, a kiosk, the downtown café, and the uptown café. The company employed 15 employees; 10 of these employees performed tasks only in the company's cafés and kiosk location; four employees perform tasks in all of the company's locations, and one employee only performed tasks in the roastery production space. The NIOSH evaluated the roastery, the downtown café, and the uptown café.

The roastery production space was approximately 1,081 square feet dedicated to green bean storage, roasting, and packaging. The roastery production space contained painted brick walls and a cement floor. A garage door was located at the front of the building, and during the spring and fall months, the man door located in the front of the building was propped open. The roastery production space housed the facility's San Franciscan roaster. Roasting was done about four hours at a time twice weekly. Approximately 300 pounds of coffee was roasted per batch. After the coffee was roasted, roughly $90 \%$ of the coffee was immediately packaged. Half of the roasted coffee was hand packed into one and five pound heat-sealed, foil-lined bags. The remainder of the roasted coffee was placed into plastic buckets and distributed to the cafés and the kiosk location. During the NIOSH survey, approximately two to three employees conducted roasting and packaging tasks.

The downtown café was approximately 725 square feet and contained a seating area and a bar where various coffee drinks were made, and pastries were served. The downtown café had a professional grade espresso machine, dual station coffee brewer, one pound professional grade coffee grinder, and two professional grade espresso grinders. Small 
amounts of roasted coffee beans were ground in the café as drinks were ordered. Twice a week, employees transported roasted coffee beans to the downtown café, and employees ground the coffee in the basement of the café using two professional grade grinders; this ground coffee was used to make the company's cold brew coffee. Grinding usually occurred in 30-minute intervals. An employee placed roughly three pounds of roasted coffee beans in each grinder at a time. To prepare the cold brew, an employee placed the ground coffee in a metal extraction container and added water; this mixture sat overnight. The following day, an employee collected the cold brew liquid extract in bottles and supplied it to the cafés.

The uptown café was approximately 950 square feet and contained a basement used for storage, a seating area, and a bar where various coffee drinks were made and pastries were served. The uptown café had a professional grade espresso machine, a single station coffee brewer, a one pound professional grade coffee grinder, and three professional grade espresso grinders. Small amounts of roasted coffee beans were ground in the café as drinks were ordered. A tap system was used at the uptown café to serve cold brew coffee.

\section{Quality Control}

In the roastery production space, coffee was periodically brewed and taste tested for quality control measures. The brewing location was located on a workbench in the corner of the roastery.

\section{Cleaning Activities}

Inside the roastery production space, employees used brooms to sweep the floor and wet or dry wipes on work and equipment surfaces. At the downtown café and the uptown café, employees used brooms to sweep the floor and wet or dry wipes on tabletops, counters, and equipment surfaces.

\section{Personal Protective Equipment}

Employees were not required to wear a company uniform, protective clothing, or respiratory protection. We did not observe any employees wearing respiratory protection during roasting or grinding activities.

\section{Methods}

We visited the roastery production space and two off-site retail cafés in May 2017. We held an opening meeting with the owner of the company, toured the three locations, collected air samples, performed a ventilation assessment, had informal interviews with employees, and conducted medical testing. At the conclusion of our site visit, we held a short closing meeting with the owner of the company. Two interim reports were sent to the company following our visit.

We had the following objectives for the health hazard evaluation:

1. Measure employees' exposure to diacetyl, 2,3-pentanedione, and 2,3-hexanedione during coffee processing and café tasks; 
2. Identify process areas or work tasks associated with emissions of diacetyl, 2,3-pentanedione, and 2,3-hexanedione;

3. Measure levels of $\mathrm{CO}$, and $\mathrm{CO}_{2}$ in all three locations;

4. Assess ventilation systems and their effect on exposure levels in all three locations;

5. Determine if employees had mucous membrane, respiratory, or systemic symptoms and the proportion of those symptoms that were work-related or aggravated by work;

6. Determine if employees had abnormal lung function tests, and

7. Compare employees' prevalence of lower respiratory symptoms and healthcare provider-diagnosed asthma to expected levels based on general population values.

\section{Industrial Hygiene Survey}

\section{Sampling Times for Alpha-Diketones}

We designed the sampling strategy to assess full-shift exposures and to identify tasks and processes that were the greatest contributors to worker exposure to alpha-diketones. Sampling was conducted over multiple days at the roasting and packaging facility and at the cafés. For diacetyl, 2,3-pentanedione, and 2,3-hexanedione, the air samples were collected over seconds, minutes, and hours. Samples collected over minutes can help inform recommendations related to short term exposure limits (STELs) and those collected over hours can help determine average concentrations that can be compared with the NIOSH RELs for diacetyl and 2,3-pentanedione. These average concentrations might not tell us about short-term peak exposures that could be relevant to respiratory health, particularly when tasks are repeated multiple times per day. Therefore, during particular tasks, we collected personal air samples over several minutes; these samples can provide information about which tasks have relatively higher exposures. To help identify point sources of chemicals, we also performed real-time sampling and collected instantaneous samples over seconds.

Employees who participated in air sampling were given the opportunity to request their individual air sampling results.

\section{Air Sampling and Analysis Using Modified Occupational Safety and Health Administration} (OSHA) Methods 1013/1016

We collected personal and area air samples for diacetyl, 2,3-pentanedione, and 2,3-hexanedione on silica gel sorbent tubes during the industrial hygiene survey over multiple days. The samples were collected and analyzed according to the modified OSHA sampling and analytical Methods 1013/1016 [OSHA 2008; OSHA 2010; LeBouf and Simmons 2017]. In accordance with the two methods, two glass silica gel sorbent tubes were connected by a piece of tubing and inserted into a protective, light-blocking cover. The tubes were connected in series to a sampling pump pulling air through the tubes at a flow rate of 50 milliliters per minute $(\mathrm{mL} / \mathrm{min})$. The sampling setup was attached to an employee's breathing zone or placed in an area basket in various places throughout each location. For full-shift sampling, we collected two consecutive 3-hour samples and calculated the TWA concentration from the two samples, assuming that the total 6-hour monitoring results reflected a full work shift (8-hour) TWA exposure. Although this may introduce some 
error, it is a conservative approach that is more protective of employees than the alternative assumption of no exposure during the last two hours of the shift. We refer to these samples as "full-shift samples" throughout this report. We also collected personal short-term task-based samples in the same manner, but the sampling pump flow rate was $200 \mathrm{~mL} / \mathrm{min}$ as detailed in OSHA Methods 1013 and 1016 [OSHA 2008; 2010]. Sampling times were dependent on the duration of the task being performed.

Analyses of the samples were performed in the NIOSH Respiratory Health Division's Organics Laboratory. The samples were extracted for one hour in 95\% ethanol: $5 \%$ water containing 3-pentanone as an internal standard. Samples were analyzed using an Agilent 7890/7001 gas chromatograph/mass spectrometer system operated in selected ion monitoring mode for increased sensitivity compared to the traditional flame ionization detector used in OSHA Methods 1013 and 1016 [LeBouf and Simmons 2017].

A limit of detection (LOD) is the lowest mass that an instrument can detect above background and is a criterion used to determine whether to report a result from a sample. The LODs for the visit were 0.01 micrograms per sample $(\mu \mathrm{g} / \mathrm{sample})$ for diacetyl, $0.012 \mu \mathrm{g} /$ sample for 2,3-pentanedione, and $0.020 \mu \mathrm{g} /$ sample for 2,3-hexanedione; these were based on the lowest mass used in the calibration curve. For a typical full-shift TWA air sample, these equate to $0.32 \mathrm{ppb}$ for diacetyl, $0.33 \mathrm{ppb}$ for 2,3-pentanedione, and $0.48 \mathrm{ppb}$ for 2,3-hexanedione. The LODs for task samples are generally higher than typical LOD values for full-shift samples since the air volumes collected during task samples are lower. When the values presented in the report are from samples below the LOD they are denoted by a " $<$ " symbol.

\section{Air Sampling and Analysis Using Evacuated Canisters}

We collected personal and area full-shift air samples and instantaneous task-based and source air samples for VOCs including diacetyl, 2,3-pentanedione, and 2,3-hexanedione using evacuated canisters. The evacuated canister sampling setup consisted of a $450-\mathrm{mL}$ evacuated canister equipped with an instantaneous flow controller that was designed for a short sampling duration (less than 30 seconds). Instantaneous samples were taken by opening the evacuated canister to grab a sample of air to help identify point sources of alpha-diketones. For task-based air samples, a NIOSH employee placed the inlet of the flow controller by the employee's personal breathing zone as they performed their work task to replicate exposure. For source air samples, a NIOSH employee placed the inlet of the flow controller directly at the source of interest.

The canister air samples were analyzed using a pre-concentrator/gas chromatograph/mass spectrometer system [NIOSH 2018b], with the addition of acetaldehyde, acetonitrile, and styrene to the list of quantified compounds. For the visit, the LODs were $0.39 \mathrm{ppb}$ for diacetyl, $0.54 \mathrm{ppb}$ for 2,3-pentanedione, and $0.96 \mathrm{ppb}$ for 2,3-hexanedione based on a threetimes dilution factor, which is typical for restricted flow controller samplers. LODs are dependent on the pressure inside each canister after the samples have been collected, and they may be higher or lower than typical LOD values. 


\section{Real-time Air Sampling}

We used RAE Systems (San Jose, CA) ppbRAE 3000 (Model \#PGM-7340) monitors to measure concentrations of total volatile organic compounds (TVOCs) in the air. The ppbRAE has a non-specific photoionization detector that responds to chemicals with ionization potentials below the energy of the lamp. This sampling was conducted to identify areas where coffee could be releasing TVOCs. Areas where higher concentrations of TVOCs are measured may benefit from further sampling to characterize specific exposures to alphadiketones. We found increased concentrations around areas where grinding occurred and near pour over areas. We also collected real-time measurements of $\mathrm{CO}_{2}, \mathrm{CO}$, temperature, and relative humidity $(\mathrm{RH})$ using TSI Incorporated (Shoreview, MN) VelociCalc Model 9555-X Multi-Function Ventilation Meters equipped with Model 982 IAQ probes.

\section{Ventilation Assessment}

Physical measurements of each facility were taken with a Model DISTO E7100i lasertape measure (Leica Geosystems AG, Heerbrugg, Switzerland) or a standard tape measure. Ventilation measurements were taken with a Model EBT731 Balometer Air Balancing Instrument (Alnor Products, TSI Incorporated, Shoreview, MN). Information on existing ventilation equipment, including make, model, and specified performance levels, was also collected when possible.

\section{NIOSH Medical Survey}

\section{Participants}

We invited all current employees to participate in the medical survey at the workplace on May 17, 2017. Participation was voluntary; written informed consent was obtained from each participant before testing. The survey included, in the order performed, a medical and work history questionnaire, quantification of exhaled nitric oxide, impulse oscillometry, and spirometry. We mailed participants their individual reports explaining their breathing test results and recommended each participant provide the information to their personal physician.

\section{Questionnaire}

We used an interviewer-administered computerized questionnaire to ascertain symptoms and diagnoses, work history at this coffee roasting and packaging facility and other coffee or flavoring companies, and cigarette smoking history. Questions on respiratory health were derived from five standardized questionnaires, the European Community Respiratory Health Survey [Burney et al. 1994; ECRHS 2014], the American Thoracic Society adult respiratory questionnaire (ATS-DLD-78) [Ferris 1978], the International Union Against Tuberculosis and Lung Disease [Burney and Chinn 1987; Burney et al. 1989], and the Third National Health and Nutrition Examination Survey (NHANES III) [CDC 1996] and NHANES 20072012 questionnaires [CDC 2018]. Some of the questions appeared on more than one of the standardized questionnaires. We also supplemented our questionnaire with additional respiratory and systemic symptom questions.

\section{Spirometry}

The purpose of the spirometry test was to determine a person's ability to move air out of 
their lungs. Test results were compared to expected normal values. The test included three measurements or calculations: 1) forced vital capacity (FVC), (the total amount of air the participant can forcefully blow out after taking a deep breath), 2) $\mathrm{FEV}_{1}$ (the amount of air that the participant can blow out in the first second of exhaling), and 3) the ratio of $\mathrm{FEV}_{1}$ to FVC. We used American Thoracic Society criteria for acceptability and repeatability [Miller et al. 2005].

We used a volume spirometer (dry rolling seal spirometer) to measure exhaled air volume and flow rates. We used equations for predicted values and lower limits of normal derived from NHANES III data to define abnormal spirometry [Hankinson et al. 1999]. We defined obstruction as an $\mathrm{FEV}_{1} / \mathrm{FVC}$ ratio less than the lower limit of normal with $\mathrm{FEV}_{1}$ less than the lower limit of normal; restriction as a normal $\mathrm{FEV}_{1} / \mathrm{FVC}$ ratio with $\mathrm{FVC}$ less than the lower limit of normal; and mixed obstruction and restriction as having $\mathrm{FEV}_{1}, \mathrm{FVC}$, and $\mathrm{FEV}_{1} / \mathrm{FVC}$ ratio all less than the lower limit of normal. We used the $\mathrm{FEV}_{1}$ percent predicted to categorize such abnormalities as mild, moderate, moderately severe, severe, or very severe [Pellegrino et al. 2005].

\section{Impulse Oscillometry}

Many occupational lung diseases (e.g., chronic obstructive pulmonary disease (COPD), asthma) involve the small airways; however, this part of the lung is difficult to evaluate noninvasively. Oscillometry is a helpful technology to understand the effects of occupational exposures on the small airways. There are no contraindications to the test as this test is conducted using regular breathing and does not require a forceful exhalation [Smith et al. 2005]. Spirometry can be normal despite respiratory symptoms or evidence of small airways disease on lung biopsy [King et al. 2011; Oppenheimer et al. 2007]; therefore, oscillometry results complement spirometry and can be used when spirometry is not possible because of a contraindication.

We used an impulse oscillometry machine (CareFusion Corp., San Diego, CA) to measure resistance $(\mathrm{R})$, the energy required to propagate the pressure wave through the airways, and reactance $(\mathrm{X})$, which reflects the viscoelastic properties of the respiratory system. The impulse oscillometry testing machine sends sound waves called pressure oscillations at different frequencies (e.g., 5 Hertz and 20 Hertz) into the airways to measure how airways respond to these small pressures. The test calculates 1) the airway resistance at different frequencies including 5 Hertz (R5) and 20 Hertz (R20), and the difference between R5 and R20 (DR5-R20); 2) the reactance at different frequencies including 5 Hertz (X5); 3) resonance frequency (Fres) which is the frequency where there is no airway reactance; and 4) the total reactance at all frequencies between 5 Hertz and the Fres. The predicted values for $\mathrm{R}$ and $\mathrm{X}$ were based on sex and age according to reference values recommended by the manufacturer [Vogel and Smidt 1994]. R5 was considered abnormal (elevated) if the measured value was equal to or greater than 140 percent of the predicted R5. X5 was considered abnormal (decreased) if the value of the predicted X5 minus measured X5 was equal to or greater than 0.15 kilopascals per liter per second $(\mathrm{kPa} /(\mathrm{L} / \mathrm{s}))$. DR5-R20 values greater than $30 \%$ were considered abnormal and evidence of frequency dependence [Smith 2015]. We interpreted the test as normal if both the R5 and X5 were normal [Smith 2015]. 
We defined possible large (central) airways abnormality as a normal X5 and elevated R5 with no evidence of frequency dependence. We defined a possible small airways abnormality if there was evidence of frequency dependence and/or a decreased X5 with or without an elevated R5. We defined possible combined small (peripheral) and large (central airways) abnormality as a decreased X5 and elevated R5 with no evidence of frequency dependence.

\section{Fractional Exhaled Nitric Oxide (FeNO)}

We used the NIOX MINO ${ }^{\circledR}$ device (Aerocrine Inc., Morrisville, NC) to measure the amount of nitric oxide in the air the participant breathed out. Nitric oxide is a gas that is produced by the airways, and elevated levels can be a sign of eosinophilic airway inflammation in asthma [Dweik et al. 2011]. In adults, fractional nitric oxide concentration in exhaled breath levels above $50 \mathrm{ppb}$ are considered elevated. In adults with asthma, elevated levels may indicate that their asthma is uncontrolled [Dweik et al. 2011].

\section{Statistical Analysis}

Industrial Hygiene Survey and Ventilation Assessment

We performed analyses using Excel (Microsoft ${ }^{\circledR}$, Redmond, WA) and SAS version 9.4 (SAS Institute Inc., Cary, NC). We created summary statistics by work area location, job title, and task. When the values presented in the report are from samples below the LOD they are denoted by a "<" symbol.

\section{Medical Survey}

We calculated frequencies and standardized morbidity ratios (SMRs) and their associated 95\% confidence intervals (CI) using SAS version 9.3 (Cary, NC). The SMRs compare prevalence of symptoms and diagnoses among participants to expected prevalence of a sample of the general population reflected in the NHANES III (1988-1994) or NHANES 2007-2012 adjusting for sex, race/ethnicity, age (less than 40 years old or 40 years or greater), and cigarette smoking categories (ever/never). For comparisons to the US population, we used the most recent NHANES survey available for the specific comparisons. The small number of participants limits the conclusions that can be drawn from these analyses. Nonetheless, we report these results to provide some context for how commonly these symptoms and diagnoses are reported by adults in the general population.

\section{Results}

\section{Industrial Hygiene Survey Results}

\section{Personal and Area Full-shift Air Sampling Results}

OSHA Methods 1013/1016

Table A1 presents the personal and area full-shift air sampling results from our visit to the two off-site retail café locations and the roastery where roasting and packaging occurred. We collected 13 personal and 37 area full-shift air samples. Five personal air samples (four from the uptown café and one from the downtown café) were above the NIOSH REL for 
diacetyl of $5 \mathrm{ppb}$, and one sample from the downtown café was above the NIOSH REL for 2,3-pentanedione of $9.3 \mathrm{ppb}$. All of these samples were collected on baristas. A downtown café employee who ground roasted coffee beans (for cold brew coffee) for approximately 30 minutes during the six hour sampling had the highest exposure to diacetyl (13.9 ppb) and 2,3-pentanedione (15.6 ppb).

Except for this employee's exposure, the employees at the downtown café generally had lower exposures to diacetyl and 2,3-pentanedione than those at the uptown café. The highest exposure to diacetyl at the uptown café was $5.8 \mathrm{ppb}$. All personal samples were below the LOD for 2,3-hexanedione.

Six of twenty-one area full-shift air samples in the cafés (three at the uptown café and three at the downtown café) were above the NIOSH REL for diacetyl. Because area air samples are not personal air samples collected directly on an employee, the NIOSH RELs are not directly applicable to the results for exposure monitoring purposes. However, area air samples can highlight areas with higher exposure risk and the RELs can be used as points of reference. The following areas at the uptown café had full-shift levels that exceeded the NIOSH REL for diacetyl: the counter near the grinders $(7.6 \mathrm{ppb})$, the front corner window seating area $(7.5$ $\mathrm{ppb})$, and the counter near the pour over area $(6.4 \mathrm{ppb})$. The following areas at the downtown café had full-shift air levels that exceeded the NIOSH REL for diacetyl: the bar between the espresso grinders and the espresso machine $(5.5 \mathrm{ppb})$, the bar near the pour over areas (5.4 $\mathrm{ppb}$ ), and the bar between the grinders and brewers (5.4 ppb). Overall, the highest full-shift average area samples for diacetyl were measured near café grinders and pour over areas. All area samples were below the NIOSH REL for 2,3-pentanedione and 2,3-hexanedione; however, one sample collected at the front corner seating area at the uptown café had a full-shift air level of $9.0 \mathrm{ppb}$ for 2,3-pentanedione. All area samples collected at the roastery production space were below the NIOSH REL for diacetyl, 2,3-pentanedione, and 2,3-hexanedione.

\section{Task-based Air Sampling Results}

Table A2 presents the results of diacetyl, 2,3-pentanedione, and 2,3-hexanedione air concentrations by location for personal 15-minute task-based samples. We collected 17 personal task-based air samples using OSHA Methods 1013/1016. Two 15-minute samples of an employee grinding roasted coffee beans at the downtown café exceeded the NIOSH STELs for both diacetyl of $25 \mathrm{ppb}$ and 2,3-pentanedione of $31 \mathrm{ppb}$, with the highest exposure to diacetyl of $124.5 \mathrm{ppb}$ and 2,3-pentanedione of $133.8 \mathrm{ppb}$. All other task-based samples were below NIOSH STELs. Two 15-minute samples of an employee grinding roasted coffee beans at the downtown café exceeded the LOD for 2,3-hexanedione; all other samples were below the LOD for 2,3-hexanedione.

\section{Instantaneous Source Air Sampling Results}

Table A3 presents the results from the six source air samples that were collected inside the downtown café during the visit in May 2017. All evacuated canisters were equipped with an instantaneous flow controller with a sample duration of approximately 30 seconds. We sampled in the basement of the downtown café and captured a sample at the grinder outlet 
while grinding was occurring. Air concentrations were $678 \mathrm{ppb}$ and $1496 \mathrm{ppb}$ for diacetyl, $729 \mathrm{ppb}$ and $1429 \mathrm{ppb}$ for 2,3-pentanedione, and $22.8 \mathrm{ppb}$ and $51.2 \mathrm{ppb}$ for 2,3-hexanedione. We captured two additional samples over the top of the cold brew metal soaking vat. Air concentrations were $33.1 \mathrm{ppb}$ and $17.7 \mathrm{ppb}$ for diacetyl, $42.3 \mathrm{ppb}$ and $21.1 \mathrm{ppb}$ for 2,3-pentanedione, and $3.9 \mathrm{ppb}$ and $<0.9 \mathrm{ppb}$ for 2,3-hexanedione. We also collected two samples inside the café at the espresso grinder and espresso machine while espresso was being made. Air concentrations were $4.9 \mathrm{ppb}$ and $23.1 \mathrm{ppb}$ for diacetyl, $5.3 \mathrm{ppb}$ and $26.4 \mathrm{ppb}$ for 2,3-pentanedione, and $<1.0 \mathrm{ppb}$ and $1.1 \mathrm{ppb}$ for 2,3-hexanedione. In the basement of the downtown café, diacetyl concentrations ranged from $17.7 \mathrm{ppb}-1496 \mathrm{ppb}$; 2,3-pentanedione concentrations ranged from $21.1 \mathrm{ppb}-1429 \mathrm{ppb}$; and 2,3-hexanedione concentrations ranged from $<0.9 \mathrm{ppb}-51.2 \mathrm{ppb}$.

\section{Instantaneous Task-Based Air Sampling Results}

Table A4 presents the results from the ten task-based air samples collected at the roastery production space during the visit in May 2017. All evacuated canisters were equipped with an instantaneous flow controller with a sample duration of approximately 30 seconds. Results should not be compared to the 15-minute STELs. We sampled one employee while dumping roasted coffee beans into a cooling pan during two different roasts. Air concentrations ranged from $0.6 \mathrm{ppb}-3.1 \mathrm{ppb}$ for diacetyl, $<0.5 \mathrm{ppb}-2.5 \mathrm{ppb}$ for 2,3-pentandedione and $<0.9 \mathrm{ppb}-$ $2.2 \mathrm{ppb}$ for 2,3-hexanedione. Another sample was captured while roasted coffee beans were being dumped into the cooling pan. Air concentrations were $<0.4 \mathrm{ppb}$ for diacetyl, 0.6 for 2,3-pentanedione, and $<1.0$ for 2,3-hexanedione. Two samples were captured during the hand blending of two types of roasted coffee in five-gallon buckets. Air concentrations were 15.5 $\mathrm{ppb}$ and $5.2 \mathrm{ppb}$ for diacetyl, $11.4 \mathrm{ppb}$ and $3.2 \mathrm{ppb}$ for 2,3-pentanedione, and $<1.0 \mathrm{ppb}$ and $<0.9 \mathrm{ppb}$ for 2,3-hexanedione during hand blending. Two additional samples were captured while packaging and weighing coffee into 5 pound bags. Air concentrations were $2.9 \mathrm{ppb}$ and $1.9 \mathrm{ppb}$ for diacetyl, $2.2 \mathrm{ppb}$ and $1.4 \mathrm{ppb}$ for 2,3-pentanedione, and $<0.9 \mathrm{ppb}$ for both samples for 2,3-hexanedione while packaging and weighing coffee into 5 pound bags. One sample was captured while coffee was being packed and weighed into bags. Air concentrations were $2.4 \mathrm{ppb}$ for diacetyl, $1.6 \mathrm{ppb}$ for 2,3-pentanedione, and $<1.0 \mathrm{ppb}$ for 2,3-hexanedione.

\section{Real-time Monitoring: Carbon Dioxide ( $\left.\mathrm{CO}_{2}\right)$, Carbon Monoxide (CO), and Total Volatile Organic Compounds (TVOCs)}

Table A5 presents the results from real-time monitoring for $\mathrm{CO}, \mathrm{CO}_{2}$, temperature, and $\mathrm{RH}$ collected during the visit. In all locations, indoor CO levels were well below the NIOSH ceiling of 200 parts per million (ppm). The highest reading of $23.7 \mathrm{ppm}$ was collected at the downtown café on the bar between the espresso grinders and espresso machine. Over the multi-day sampling period, the average $\mathrm{CO}_{2}$ levels were $1,468 \mathrm{ppm}$ at the uptown café, $1,214 \mathrm{ppm}$ at the downtown café, and $583 \mathrm{ppm}$ at the roastery production space. The average outdoor $\mathrm{CO}_{2}$ level was $447 \mathrm{ppm}$. During the visit, total VOCs were recorded at the cafés. At the downtown café the following peak total VOC concentrations were observed; 2,523 ppb on the bar between the espresso grinder and machine (May 16, 2017 at 2:25pm), 3,486 ppb on the bar between the grinders and brewers (May 17, 2017 at 8:37am), and $544 \mathrm{ppb}$ in the basement next to the grinders (May 18, 2017 at 8:44am). At the uptown café the following peak total VOC concentrations were observed; $1,661 \mathrm{ppb}$ on the counters near the grinders 
(May 16, 2017 at 11:15am), 1,285 ppb on the counter near the grinders (May 17, 2017 at 11:27am), and 1,357 ppb on the counters near the grinders (May 18, 2017 at 12:09pm) and $1,378 \mathrm{ppb}$ on the counter near the pour over area (May 18, 2017 at 9:26am). At the roastery production space total VOCs were only collected on May 18, 2017 in two locations; on the table near the roaster and on the weighing table. A peak total VOC concentrations of $77 \mathrm{ppb}$ was observed on the table near the roaster $(1: 07 \mathrm{pm})$ and a peak of $533 \mathrm{ppb}$ was observed on the weighing table (11:48am).

\section{Ventilation Assessment}

\section{Roastery}

Ventilation, heating, and cooling at the roastery was provided by a single Nordyne (Nortek Global HVAC, LLC, O' Fallon, MO) Model B6BMM030K-B air handling unit (AHU). The unit was mounted on the northeastern wall and fed a single galvanized sheet metal supply duct running from the unit to the southwest along the ceiling of the space. The supply duct fed eight 4-inch by 10-inch supply vents over its length, although one vent at the far end of the duct was completely covered with tape. Return air was pulled back to the unit through a single 15 -inch by 20 -inch opening at the bottom of the unit. The return opening was covered with a single 14 -inch $\times 20$-inch $\times 1$-inch pleated air filter (brand and efficiency level unknown). The air filter in place was discolored from a substantial amount of collected particulate matter. The filter was also smaller than the return opening to the AHU, so a considerable amount of return air was bypassing the filter. The roastery AHU was controlled by a wall-mounted thermostat and was operated as desired by employees in the area. The unit was generally off, but when powered on, it circulated 1145 cubic feet per minute $(\mathrm{cfm})$ of air throughout the space. However, the air being moved was $100 \%$ recirculated air from the roasting space with no fresh, outdoor air (as is common in homes). The San Franciscan roaster located in the space was ducted to the outdoors. There were no visible signs of smoke while the roaster was operating.

\section{Uptown Café}

The uptown café was heated, cooled, and ventilated with one Armstrong Air (West Columbia, SC) Model BSC2M24C00NA1P-1 AHU installed in a largely unfinished portion of the basement. Supply air from the unit flows through a fiberglass-wrapped galvanized sheet metal main supply duct and some fiberglass flexible ductwork to ten 11-inch $\times 5$-inch supply vents installed in the floor around the perimeter of the first-floor café space. Return air was pulled back to the AHU through two 26-inch $\times 12$-inch grilles installed in the vertical wall separating the café serving area from the bathroom. Fiberglass-wrapped galvanized sheet metal ducts carried the return air back to the unit in the basement. The AHU in the uptown café was controlled by a wall-mounted thermostat behind the serving bar and it cycled on and off depending on the temperature set-point. When powered on, the AHU recirculated $610 \mathrm{cfm}$ throughout the café space without supplying any fresh, outdoor air.

\section{Downtown Café}

The downtown café was heated, cooled, and ventilated by a combination system installed horizontally in the basement of the building. Heating and air movement was provided by an Allied Air (West Columbia, SC) Model 95G1UHD Furnace. Air conditioning was provided 
by an attached Rheem (Fort Smith, AR) Model RCFL-HM3617CC indoor coil unit. Supply air through the combination system traveled through an insulated galvanized sheet metal main duct and fiberglass flexible ductwork branches to eight 16 -inch $\times 5$-inch supply vents installed in the floor around the perimeter of the first-floor café space. Return air was pulled back to the AHU through a single 14-inch $\times 12$-inch grille in the floor behind the café serving bar. Fiberglass-wrapped galvanized sheet metal ducts carried the return air back to the unit in the basement. The downtown café AHU was controlled by a wall-mounted thermostat that cycled the unit on and off depending on the temperature set-point. When powered on, the AHU recirculated $1070 \mathrm{cfm}$ throughout the café space without supplying any fresh, outdoor air. No mechanical ventilation supply vents or return grilles served the basement of the building.

\section{Medical Survey Results}

\section{Demographics}

Nine of 15 employees $(60 \%)$ participated in the medical survey. The majority of participants were male (67\%) and Caucasian (89\%), with a mean age of 27 years and average tenure at the company of two years. Three (33\%) participants worked at another coffee roasting and packaging facility or café prior to working at this facility. Three $(33 \%)$ participants were current or former smokers.

Five of the nine participants reported working in or entering the roastery production area during an average work week. Four of the five production area participants reported that they ground coffee beans and moved roasted or ground coffee. These participants reported being within arm's length of cooling bins that contain roasted beans while they are cooling. Eight of the nine total participants reported being within arm's length of production hoppers, bins, or containers of roasted coffee other than cooling bins.

Eight of the nine total participants reported working in the cafés. All café participants reported that they do not roast coffee beans inside the cafés, but they do grind coffee beans inside the cafés.

\section{Symptoms and Self-Reported Diagnoses}

The prevalence of symptoms over the last year and last four weeks at the time of the survey are listed in Table A6. Nose symptoms were the most commonly reported symptom $(\mathrm{n}=9$, $100 \%)$, followed by eye symptoms $(n=7,78 \%)$ and sinusitis or sinus problems $(n=3,33 \%)$. Two participants reported improvement in their symptoms away from the workplace. One employee reported that their symptoms were caused or aggravated by dust; all other employees did not identify a source that maybe causing or aggravating their symptoms.

Wheeze was the most commonly reported lower respiratory symptom ( $n=3,33 \%$ ) (Table A6). None reported improvement in wheeze away from the workplace. Flu-like achiness or achy joints and fever or chills were the most commonly reported systemic symptom $(n=6,67 \%)$. Two $(22 \%)$ participants reported that their systemic symptoms were better when away from work. 
Three participants reported a diagnosis of hay fever or nasal allergies; two reported asthma; two reported eczema, dermatitis or skin allergy; and one reported gastroesophageal reflux disease. All these conditions, except for the gastroesophageal reflux disease, were diagnosed prior to employment at the coffee roasting and packaging facility and cafés. No participants reported a diagnosis of chronic bronchitis, emphysema, COPD, bronchiolitis obliterans, interstitial lung disease, hypersensitivity pneumonitis, chemical pneumonitis, sarcoidosis, heart disease, or vocal cord dysfunction.

\section{Medical Tests}

All spirometry tests were interpreted at normal. There were three impulse oscillometry tests interpreted with abnormalities: one with a possible large airways abnormality; one with a possible small airways abnormality, and one with possible a small and large airways abnormality. One exhaled nitric oxide test was interpreted as elevated.

\section{NHANES Comparison of Symptoms, Diagnoses, and Spirometry}

The prevalence of selected symptoms (including wheeze and shortness of breath) and diagnoses (including asthma) among participants was not different than expected from comparisons to the general US population (Table A7).

\section{Discussion}

At the roastery production space and the two off-site retail cafés that are the subject of this report, the highest area samples for total VOCs, CO, diacetyl, and 2,3-pentanedione were observed in areas where coffee was ground (near coffee and espresso grinders) or near pour over areas. Diacetyl, 2,3-pentanedione, 2,3-hexanedione, other VOCs, and other chemicals such as $\mathrm{CO}$ and $\mathrm{CO}_{2}$ are naturally produced when coffee beans are roasted, and grinding the roasted coffee beans produces greater surface area for the off-gassing of these chemicals [Anderson et al. 2003; Akiyama et al. 2003; Daglia et al. 2007; Newton 2002; Nishimura et al. 2003; Raffel and Thompson 2013]. Occupational exposure to diacetyl and 2,3-pentanedione can cause loss of lung function and the lung disease obliterative bronchiolitis [NIOSH 2016]. As of the date of this report, no cases of obliterative bronchiolitis have been reported in coffee café workers.

\section{Alpha-Diketones}

\section{Personal Air Sampling}

Five personal (all baristas, four from the uptown café, and one from the downtown café) full-shift air samples taken inside the three locations using standard OSHA methods were above the NIOSH REL for diacetyl. The highest full-shift personal exposure to diacetyl was 13.9 ppb collected from a barista at the downtown café who ground roasted coffee beans for approximately 30 minutes during the full shift sampling. This elevated average exposure was likely due to peak exposures that occurred during grinding coffee beans combined with periods of lower exposures. As noted earlier, the REL should be used as a guideline to indicate when steps should be taken to reduce exposures in the workplace. The risks 
associated with the measured levels are higher than NIOSH recommends. As described in the quantitative risk assessment from the NIOSH Criteria Document (Tables 5-27 and 5-34) [NIOSH 2016], after a 45-year working lifetime exposure to $10 \mathrm{ppb}$ (a concentration lower than the highest concentration measured at this facility), NIOSH estimated that about 3 in 1,000 workers would develop reduced lung function ( $\mathrm{FEV}_{1}$ below the lower limit of normal). NIOSH predicted that 2 in 10,000 workers exposed to diacetyl at $10 \mathrm{ppb}$ would develop more severe lung function reduction $\left(\mathrm{FEV}_{1}\right.$ below $60 \%$ predicted, defined as at least moderately severe by the American Thoracic Society [Pellegrino et al. 2005]). After a 45-year working lifetime exposure to $20 \mathrm{ppb}$ (a concentration higher than the highest concentration measured at this facility), NIOSH estimated that 5 in 1,000 workers would develop reduced lung function ( $\mathrm{FEV}_{1}$ below the lower limit of normal). NIOSH predicted that 5 in 10,000 workers exposed to diacetyl at $20 \mathrm{ppb}$ would develop more severe lung function reduction. The effects of a working lifetime exposure at $13.9 \mathrm{ppb}$ would bebetween those for $10 \mathrm{ppb}$ and $20 \mathrm{ppb}$. NIOSH recommends keeping diacetyl concentrations below 5 ppb because at this level, the risk of reduced lung function after a working lifetime of exposure is below 1 in 1000 workers. NIOSH recommends taking steps to reduce diacetyl exposures to below the REL of 5 ppb whenever possible.

\section{Area Air Sampling}

Of the 37 full-shift area samples, six were above the NIOSH REL for diacetyl. Areas at both the uptown café (the counter near the grinders $[7.6 \mathrm{ppb}]$, the front corner window seating area [7.5 ppb], and the counter near the pour over area [6.5 ppb]) and the downtown cafe (the bar between the espresso grinders and the espresso machine [5.5 ppb], the bar near the pour over areas [5.4 ppb], and the bar between the grinders and brewers [5.4 ppb]) had air levels that exceeded the NIOSH REL for diacetyl. In each café, locations near café grinders and pour over areas had the highest diacetyl air levels; uptown café (7.6 ppb-6.4 ppb) and downtown café $(5.5 \mathrm{ppb}-5.4 \mathrm{ppb})$. We note that NIOSH RELs are intended to be directly compared to personal measurements; therefore, an area air sample that exceeds a NIOSH REL is only an indication of potential personal exposures.

\section{Task-Based Exposures}

Coffee processing involves multiple tasks that may cause intermittent exposure to diacetyl and 2,3-pentanedione. Traditional full-shift sampling will not characterize these intermittent, peak exposures. Evaluating intermittent and task-based exposures to diacetyl and 2,3-pentanedione is difficult with current validated sampling methods (OSHA Methods 1013/1016). Since tasks are so sporadic in coffee processing, with some only lasting a few seconds or minutes, we used instantaneous evacuated canisters to sample tasks that were only a few seconds to minutes long and OSHA Methods 1013/1016 for longer duration tasks. We sampled by task, with varying durations, to understand which tasks may have contributed to higher exposures to diacetyl and 2,3-pentanedione.

Our task-based air sampling revealed that grinding roasted coffee beans had higher air concentrations of diacetyl and/or 2,3-pentanedione than any other tasks. During our visit, using OSHA Methods 1013/1016 over two separate 15-minute sampling periods grinding roasted coffee tasks, in the basement at the downtown café where the cold brew was made for 
both cafés, had the highest levels of diacetyl (80.9 ppb and $124.5 \mathrm{ppb})$ and 2,3-pentanedione (87.4 ppb and $133.8 \mathrm{ppb}$ ). We also captured instantaneous evacuated canisters taskbased samples at the roastery production space during tasks of dumping, hand blending, and packaging coffee. We observed that hand blending two types of roasted coffee in 5 gallon buckets resulted in the highest diacetyl (maximum $15.5 \mathrm{ppb}$ ) and 2,3-pentanedione (maximum $5.2 \mathrm{ppb}$ ) air concentrations compared to other tasks.

\section{Source-Based Exposures}

During the visit, instantaneous evacuated canisters source-based samples were captured at the downtown café in the basement at the cold brew grinder outlet and over the cold brew soaking vat and inside the café at the espresso grinder and espresso machine. We observed that at the grinder outlet and over the cold brew soaking vat in the basement resulted in the highest diacetyl ( $\max 1496 \mathrm{ppb})$ and 2,3-pentanedione (max $1429 \mathrm{ppb})$ air concentrations compared to other tasks. Instantaneous evacuated canisters source-based samples were not collected at the uptown café or the roastery production space. During our visit, we observed that levels of $\mathrm{CO}$ and $\mathrm{CO}_{2}$ at each location were within the OSHA, ACGIH, and NIOSH personal exposure limits described in Table A1.

\section{Ventilation}

The personal air sampling results, supported by the area air sampling results, indicated the existing roastery ventilation system was effective at controlling airborne concentrations of alpha-diketones below the NIOSH RELs during our visit. If the amount of coffee roasted and packaged in the roastery increases substantially in the future, additional ventilation may become necessary.

An adequate supply of outdoor air, typically delivered through the HVAC system, is necessary in any indoor environment to dilute pollutants that are released by equipment, building materials, furnishings, products, and people. $\mathrm{CO}_{2}$ is a normal constituent of exhaled breath; thus, $\mathrm{CO}_{2}$ will also increase during building occupancy. $\mathrm{CO}_{2}$ levels are routinely collected in air quality studies because they can indicate whether a sufficient quantity of outdoor air is being introduced to an occupied space for acceptable odor control. The American National Standards Institute (ANSI) and ASHRAE have developed consensus standards and guidelines for HVAC systems. ASHRAE notes in an informative appendix to ANSI/ASHRAE Standard 62.1-2016: Ventilation for Acceptable Indoor Air Quality that indoor $\mathrm{CO}_{2}$ concentrations no greater than $700 \mathrm{ppm}$ above outdoor $\mathrm{CO}_{2}$ concentrations will satisfy a substantial majority (about $80 \%$ ) of occupants [ANSI/ASHRAE 2016]. This would typically correspond to indoor concentrations below 1,200 ppm since outdoor $\mathrm{CO}_{2}$ concentrations usually range between 375 to $500 \mathrm{ppm}$. However, $\mathrm{CO}_{2}$ is not an effective indicator of ventilation adequacy if the ventilated area is not occupied at its usual occupant density at the time the $\mathrm{CO}_{2}$ is measured, or if the occupancy level changes frequently over time, like in a café. Elevated $\mathrm{CO}_{2}$ concentrations suggest that other indoor contaminants may also be increased. If $\mathrm{CO}_{2}$ concentrations are elevated, the amount of outdoor air introduced into the ventilated space may need to be increased.

Four of five personal sampling results from workers in the uptown café measured exposures 
to diacetyl at levels above the NIOSH REL. This clearly indicates that the existing ventilation system was ineffective at controlling exposures to acceptable levels, most likely because the existing ventilation system did not provide any fresh, outdoor air to the space. This is further supported by the average $\mathrm{CO}_{2}$ concentration being $1470 \mathrm{ppm}$ throughout multiple days of sampling in the café. Concentrations of $\mathrm{CO}_{2}$ at these levels are indicative of a lack of outdoor air supplied to the space, and they can result in the space feeling "stale" or "stuffy."

In some cases, building owners/managers or occupants will open doors or windows to increase the amount of outdoor air coming into their building. However, relying on open doors may cause problems. For example, the air coming into the building through the doors may not reach all of the occupied space. The incoming air is unfiltered and may contain outdoor air pollutants such as pollen and dust. Additionally, open doors may affect the ability of the HVAC system to adequately control temperatures and humidity. ASHRAE guidelines provide specific details on ventilation for acceptable indoor environmental quality. A ventilation system expert can help meet ASHRAE ventilation guidelines in the building. ANSI/ASHRAE 62.1-2016 recommends outdoor air supply rates that take into account people-related sources as well as building-related sources. While there are no specific recommendations in the standard for coffee cafés, there are several similar spaces that can be used as effective guidance. For restaurant dining rooms, café/fast-food dining, and bars and cocktail lounges, $7.5 \mathrm{cfm} /$ person is recommended for people-related sources, and an additional $0.18 \mathrm{cfm}$ for every square foot $\left(\mathrm{cfm} / \mathrm{ft}^{2}\right)$ of occupied space is recommended to account for building-related sources. To find rates for other indoor spaces, refer to Table 6.2.2.1, which is found in ANSI/ASHRAE 62.1-2016 [ANSI/ASHRAE 2016]. A qualified ventilation contractor can help with ways to modify the existing ventilation system to bring in appropriate levels of outdoor air to reduce indoor alpha-diketone and $\mathrm{CO}_{2}$ concentrations in the uptown café. Using ASHRAE Standard 62.1-2016 as a guide, given the floor space of the café, roughly $300 \mathrm{cfm}$ of outdoor air should be introduced to the space at maximum occupancy.

The personal sampling results for employees in the downtown café were all below the NIOSH RELs for diacetyl and 2,3-pentanedaione, except for one employee that spent a significant amount of time grinding coffee for cold brew in the unventilated basement of the building. In the main café space, the average multi-day $\mathrm{CO}_{2}$ concentration was $1178 \mathrm{ppm}$, which is approaching levels that would indicate a lack of appropriate outdoor air ventilation. This was expected since the existing ventilation system does not provide any fresh, outdoor air to the space. According to ASHRAE Standard 62.1-2016, roughly $300 \mathrm{cfm}$ of outdoor air should be provided to the space continuously to meet demand at maximum occupancy.

High concentrations of alpha-diketones were measured at the basement cold brew grinder. Grinding coffee for cold brew in the unventilated basement of the downtown café is an issue that should be specifically addressed. A local exhaust ventilation (LEV) system should be designed and installed to capture alpha-diketones released during cold brew grinding. LEV systems capture contaminants at the source and exhaust them before inhalation by employees occurs. LEV systems generally consist of hoods or enclosures, duct work, or fans. Depending on the contaminant and whether air is recirculated, filters or other air cleaning technologies 
can be incorporated. When properly designed local exhaust ventilation systems are installed, overall workplace exposure levels can be reduced by removing contaminants at the source. Work with a ventilation engineer to reduce alpha-diketone exposures at the cold brew grinder. Relocating the cold brew grinder closer to an exterior wall could make it easier to enclose the grinding process and reduce costs associated with ventilating the process separately.

\section{Medical Survey}

Overall, mucous membrane symptoms, specifically nose, eye, and sinus symptoms, were the most commonly reported symptoms. One employee who works in all locations reported their mucous membrane symptoms were caused or aggravated by dust. Coffee dust is an organic dust known to cause respiratory symptoms [Zuskin et al. 1993; Sakwari et al. 2013]. Green and roasted coffee dust and castor beans (from cross-contamination of bags used to transport coffee) are known risk factors for occupational asthma [Figley and Rawling 1950; Karr et al. 1978; Zuskin et al. 1979, 1985; Thomas 1991]. Persons who become sensitized (develop an immune reaction) to coffee dust can subsequently react to relatively low concentrations in the air. Others may experience irritant-type symptoms from exposure to coffee dust [Oldenburg et al. 2009].

Upper respiratory disease such as allergic rhinitis (hay fever, nasal allergies) and sinusitis are sometimes associated with lower respiratory symptoms and asthma and may precede the diagnosis of asthma [Shaaban et al. 2008; EAACI Task Force on Occupational Rhinitis et al. 2008; Rondón et al. 2012, 2017; Sahay et al. 2016]. Upper respiratory involvement (e.g., rhinitis, sinusitis) can result in suboptimal control of asthma. Two of the five participants that reported lower respiratory symptoms also reported nasal, sinus problems, or physiciandiagnosed hay fever or nasal allergies. Green coffee dust is thought to be a more potent allergen than roasted coffee dust because roasting destroys some of the allergenic activity [Lehrer et al. 1978]. As discussed in the recommendations section, to prevent symptoms related to green coffee dust and chaff, make N-95 disposable filtering-face piece respirators available for voluntary use when emptying burlap bags of green beans into the roaster, storage containers, or cleaning the green bean storage area in the roastery production space.

The number of participants with physician-diagnosed asthma was not different from that observed in the U.S. population. However, $56 \%(n=5)$ of participants (including participants with asthma) reported one or more lower respiratory symptoms in the 12 months prior to the medical survey. None of these participants perceived their lower respiratory symptoms as work-related. Asthma symptoms often improve when away from exposures that trigger symptoms while other lung diseases such as obliterative bronchiolitis or COPD generally do not improve. Spirometry can be used to help detect and follow individuals with asthma and other lung diseases such as obliterative bronchiolitis or COPD. Spirometry can show if air is exhaled from the lungs more slowly than normal (i.e. obstructive abnormality) or if the amount of air exhaled is smaller than normal (i.e., restrictive abnormality). In asthma, there is intermittent airways obstruction which is reversible after treatment with bronchodilator medications (e.g., albuterol). In obliterative bronchiolitis, scar tissue prevents the small airways (bronchioles) from opening up when albuterol is given. In other words, the airways are fixed and not responsive (reversible) to bronchodilator medicine. The obstructed airways 
prevent rapid emptying of the lung air sacs (alveoli) during exhalation. This explains why the respiratory symptoms of those with occupational obliterative bronchiolitis do not tend to improve when away from work-related exposures; however, avoidance of further exposure can stop progression of the disease [Akpinar-Elci et al. 2004].

Spirometry and impulse oscillometry measure different things. Spirometry assesses airflow and is the breathing test typically used to screen for flavoring-related lung disease. Impulse oscillometry accesses the airways response to a sound or pressure wave and has not commonly been used to screen for flavoring-related lung disease. In general, during the impulse oscillometry test, a small pressure impulse (sound wave) is imposed upon the inspiratory and expiratory airflow during normal tidal breathing. This pressure wave causes a disturbance in the airflow and pressure, and the response of the airways (i.e., change in pressure to change in flow) is a measure of the resistance to airflow in the airways [Desiraju and Agrawal 2016]. Impulse oscillometry may be useful as an indirect measure of airflow obstruction and helpful in individuals not able to perform forced breathing maneuvers that are required during the spirometry test. The impulse oscillometry test has been used for many years to measure changes in the airways of children with lung problems such as asthma and cystic fibrosis [Song et al. 2008; Komarow et al. 2011; Shi et al. 2012; Schulze et al. 2016]. More recently, impulse oscillometry has been used to investigate lung problems in adults exposed to dust or chemicals, such as World Trade Center emergency responders and soldiers returning from deployment overseas [Oppenheimer et al. 2007; Berger et al. 2013; Weinstein et al. 2016]. Over the years, researchers have developed reference (predictive) equations for different populations of children for oscillometry [Malmberg et al. 2002; Park et al. 2011; Lee et al. 2012; de Assumpção et al. 2016]. For adults, there are fewer reference equations available for oscillometry [Vogel and Smidt 1994; Newbury et al. 2008; Schulz et al. 2013]. The predicted values we used for oscillometry measures were based on gender and age according to references values recommended by the manufacturer. Unlike predictive equations used for spirometry, the impulse oscillometry reference equations we used did not take into account height, race, or smoking status [Vogel and Smidt 1994].

We did not find any abnormalities on spirometry among the nine participants. One of the nine spirometry tests had a reduction in the $\mathrm{FEV}_{1} / \mathrm{FVC}$ ratio but was still within normal limits. However, a majority of participants reported at least one lower respiratory symptom. Impulse oscillometry was abnormal in three participants, and exhaled nitric oxide was elevated in one participant. These lower respiratory symptoms and breathing test abnormalities are not specific to a particular respiratory problem or disease. They could be related to workplace exposures or to other factors. Indeed, some employees had respiratory diagnoses that preceded employment at this facility. Because of the small number of participants and the need to protect individuals' privacy, we cannot provide more detailed results that might shed light on possible work-relatedness, such as health measures by job title or task. We mailed each participant their individual lung function test results with an explanation of the results and recommended each participant provide the information to their personal physician.

We recommend starting a medical monitoring program because air sampling detected employee exposures to diacetyl and 2,3-pentanedione that exceeded the NIOSH REL. All 
café employees, particularly those working in the uptown café and those who work in the basement of the downtown café, where cold brew is produced, should participate in the workplace medical monitoring program. A medical monitoring program is a means of early identification of employees who may be developing lung disease (e.g., asthma, obliterative bronchiolitis) and can help prioritize interventions to prevent occupational lung disease. The NIOSH medical survey results can serve as a baseline for employees who participated, if they choose to share these results with the provider. In a workplace with risk of occupational lung disease, prevention of smoking-related lung disease is important and makes the detection of work-related adverse effects easier. The Centers for Disease Control and Prevention offers tools and resources for setting up a smoking cessation program [CDC 2018].

\section{Conclusions}

We identified specific work tasks that resulted in air concentrations of diacetyl that exceeded the NIOSH REL and STEL. Five of the 13 personal air samples were above the NIOSH REL for diacetyl of $5 \mathrm{ppb}$. All five personal air samples with diacetyl concentrations above the NIOSH REL were collected on employees with primary job duties at the cafés. High fullshift and task-based diacetyl and 2,3-pentanedione exposure measurements were observed on café baristas and one employee who performed grinding for 30 minutes in the basement during full shift sampling. Areas with ground coffee present, specifically near the grinders in the downtown café and the cold brew soak vat in the basement had the highest levels of diacetyl, 2,3-pentanedione, and 2,3-hexanedione. We observed high instantaneous levels of diacetyl and 2,3-pentanedione during grinding. CO levels were low at all the locations.

The personal and area sampling results indicated the existing roastery ventilation system was effective at controlling airborne concentrations of alpha-diketones below the NIOSH RELs, at least for the amount of coffee processed during our visit. However, the ventilation systems in both café spaces should be modified to supply some fresh, outdoor air to the occupied spaces. In both cafés, supplying around $300 \mathrm{cfm}$ of fresh, outdoor air would help reduce airborne alpha-diketone and $\mathrm{CO}_{2}$ concentrations at maximum occupancy levels. All four personal sampling results from employees in the uptown café and one of the five personal sampling results from employees at the downtown café measured exposures to diacetyl at levels above the NIOSH REL. Introducing fresh, outdoor air to the cafés would help reduce these exposures, but additional sampling for airborne diacetyl and 2,3-pentanedione should be conducted to ensure exposures are consistently below the REL after ventilation renovations are made. If exposures are still elevated, additional dilution ventilation and/or LEV may be required.

Grinding coffee for cold brew in the unventilated basement of the downtown café is an issue that should be specifically addressed. A LEV system should be designed and installed to capture alpha-diketones released during cold brew grinding. Relocating the cold brew grinder closer to an exterior wall could make it easier to enclose the grinding process and reduce costs associated with ventilating the process separately. 
Overall, mucous membrane symptoms, specifically nose, eye, and sinus symptoms, were the most commonly reported symptoms. One employee who works in all locations reported their mucous membrane symptoms were caused or aggravated by dust. Wheezing or whistling in the chest was the most commonly reported lower respiratory symptom. All spirometry tests were interpreted as normal. One of nine participants had high exhaled nitric oxide, a marker of allergic airways inflammation. Three of nine participants had impulse oscillimetry tests with possible abnormalities. We recommend a medical monitoring program to identify any employees who may be developing lung disease (e.g., asthma, obliterative bronchiolitis) and to help management prioritize interventions to prevent occupational lung disease. All employees who work in the cafés should participate in the workplace medical monitoring program.

\section{Recommendations}

On the basis of our findings, we recommend the actions listed below. We encourage this company to use a labor-management health and safety committee or working group to discuss our recommendations and develop an action plan. Our recommendations are based on an approach known as the hierarchy of controls. This approach groups actions by their likely effectiveness in reducing or removing hazards. In most cases, the preferred approach is to eliminate hazardous materials or processes and install engineering controls to reduce exposure or shield employees.

\section{Engineering Controls}

Engineering controls reduce employees' exposures by removing the hazard from the process or by placing a barrier between the hazard and the employee. Engineering controls protect employees effectively without placing primary responsibility of implementation on the employee.

\section{Downtown café}

1. Consult with a qualified ventilation engineer to design and install local exhaust ventilation around the cold brew grinder in the basement of the downtown café to exhaust contaminants generated during grinding directly outdoors. Consider moving the grinder closer to an outside wall to make the installation of LEV easier and cheaper. Operate the new LEV system at all times during cold brew grinding and brewing activities. If the new LEV system does not reduce short-term exposures to diacetyl and 2,3-pentanedione below the NIOSH STELs, additional dilution ventilation, including some fresh, outdoor air, may also be required.

2. Work with a ventilation expert to bring in appropriate levels of outdoor air to meet ASHRAE ventilation guidelines into the downtown café. Using ASHRAE Standard 62.1-2016 as a guide, given the floor space of the cafés, roughly $300 \mathrm{cfm}$ of fresh,outdoor air should be introduced to the space at maximum occupancy.

3. If these engineering controls do not reduce air concentrations of alpha-diketones, work with a ventilation engineer to install local exhaust ventilation associated with café grinding tasks. 


\section{Uptown Café}

1. Work with a ventilation expert to bring in appropriate levels of outdoor air to meet ASHRAE ventilation guidelines into the uptown café. Using ASHRAE Standard 62.12016 as a guide, given the floor space of the cafés, roughly $300 \mathrm{cfm}$ of outdoor air should be introduced to each space at maximum occupancy.

2. Conduct follow-up air sampling to verify that the ventilation system modifications have been effective in reducing $\mathrm{CO}_{2}$ levels below ASHRAE guidelines and alphadiketone exposures to below the NIOSH RELs. If diacetyl and 2,3-pentanedione concentrations are not maintained below the RELs, additional engineering controls may be necessary.

3. If these engineering controls do not reduce air concentrations of alpha-diketones, work with a ventilation engineer to install local exhaust ventilation associated with café grinding tasks.

\section{$\underline{\text { Roastery }}$}

1. Operate the ventilation system in the production space continuously during roastery operating hours.

\section{Administrative Controls}

Administrative controls are employer-dictated work practices and policies implemented to reduce or prevent hazardous exposures. Their effectiveness depends on employer commitment and employee acceptance. Regular monitoring and reinforcement are necessary to ensure that policies and procedures are followed consistently.

\section{$\underline{\text { Roastery }}$}

1. Provide an alternative method to hand-blending roasted coffee beans that minimizes employee contact with roasted beans during blending.

2. Eliminate the use of dry sweeping as much as possible during cleaning; particularly in areas where green beans are stored. Instead, use a vacuum system with a highefficiency particle air filter and wet methods whenever possible.

\section{Roastery \& Downtown and Uptown Cafés}

1. Educate employees not to place their faces right in front of or right above freshly ground coffee.

2. Ensure employees understand potential hazards (e.g., diacetyl, 2,3-pentanedione, $\mathrm{CO}$, $\mathrm{CO}_{2}$, green and roasted coffee dust) in the workplace and how to protect themselves. OSHA's Hazard Communication Standard, also known as the "Right to Know Law" [29 CFR 1910.1200] requires that employees are informed and trained on potential work hazards and associated safe practices, procedures, and protective measures.

3. Ensure employees are educated to consider the risks of further exposure if they develop lower respiratory symptoms (e.g., cough, shortness of breath, wheezing) 
that are progressive and severe in degree. Employees should report new, persistent, or worsening symptoms to their personal healthcare providers and to a designated individual at this workplace. Employees with new, persistent, or worsening symptoms should share this report with their healthcare providers.

\section{Personal Protective Equipment}

The effectiveness of respiratory protection as personal protective equipment depends on avoiding breakdowns in implementation that can cause insufficient protection from respiratory exposures. Proper use of respiratory protection (respirators) requires a comprehensive respiratory protection program and a high level of employee and management involvement and commitment to assure that the right type of respirator is chosen for each hazard, respirators fit users and are maintained in good working order, and respirators are worn when they are needed. Supporting programs such as training, change-out schedules, and medical assessment might be necessary. Respirators should not be the sole method for controlling hazardous inhalation exposures. Rather, respirators should be used until effective engineering and administrative controls are in place.

\section{Basement of Downtown Café}

1. In addition to engineering and administrative controls, respiratory protection is an option to further reduce exposures to alpha-diketones (e.g., diacetyl and 2,3-pentanedione). If follow-up air sampling, after engineering controls have been installed, indicates levels of diacetyl or 2,3-pentanedione above their respective NIOSH RELs and STELs, we recommend that respiratory protection be used during tasks with elevated exposures. Respirators used to reduce exposures to diacetyl and 2,3-pentanedione should be NIOSH-certified and equipped with organic vapor cartridges. The choice of respirator should be guided by personal exposure sampling for diacetyl and 2,3-pentanedione [NIOSH 2004]. Respirators have assigned protection factors (APFs). APF refers to the highest level of protection a properly selected respirator can provide. For reference, air-purifying half-face respirators have an APF of 10, and air-purifying full-face respirators have an APF of 50. Also, there are powered-air purifying respirators that have APFs of 25, 50, or 1000. The OSHA APFs can be found in Table 1 of OSHA Respiratory Protection Standard at https://www.osha.gov/pls/oshaweb/owadisp.show document?p id=12716\&p $\underline{\text { table}=\text { STANDARDS }}$.

If mandatory respiratory protection is used, a written respiratory protection program should be implemented as required by the OSHA Respiratory Protection Standard (29 CFR 1910.134), or the equivalent state standard in states with Federal OSHAapproved State Occupational Safety and Health plans.

\section{Roastery}

1. Make N95 disposable filtering-face piece respirators available for voluntary use for protection against green or roasted coffee dust exposure such as when emptying burlap 
bags of green beans, when cleaning the exhaust system of chaff, when emptying the chaff containers, or cleaning the green bean storage area. N95 respirators should be available in various sizes, and each potential N95 users should receive a copy of Appendix D of the OSHA Respiratory Protection Standard (or equivalent State OSHA Agency document) (https://www.osha.gov/laws-regs/regulations/standardnumber/191 $\underline{0 / 1910.134 A p p D})$. Information about Appendix D and voluntary use of respirators can be found on the OSHA website at https:/www.osha.gov/video/respiratory protection/ voluntaryuse transcript.html.

Please be aware that N95s are not protective against alpha-diketones (diacetyl, 2,3-pentanedione, or 2,3-hexanedione). In cases of dual exposure to dust and alphadiketones, NIOSH-certified organic vapor cartridges (for the alpha-diketones) and particulate cartridges/filters (for the dust) would be warranted.

\section{Medical Monitoring}

The purpose of a medical monitoring program is to help assure the health of employees who have workplace exposures (e.g., diacetyl, 2,3-pentanedione, green coffee beans/dust) known to pose risk for potentially serious health conditions such as asthma or obliterative bronchiolitis.

\section{Cafés}

1. Institute a medical monitoring program for employees who work or assist in the cafés. The medical monitoring should consist of evaluation with a questionnaire (to obtain health and work task information) and spirometry (to assess lung function) at baseline and at one year to monitor for respiratory symptoms and to establish employees' baseline in lung function and any abnormal decline in lung function in the first year. Subsequently, an annual questionnaire evaluation should occur to monitor for respiratory symptoms. New or worsening respiratory symptoms should prompt additional evaluation including spirometry. Details about spirometry and a medical monitoring program can be found in chapter 9 of the NIOSH Criteria Document [NIOSH 2016].

2. If an employee is identified as likely having lung disease from exposure to diacetyl or 2,3-pentanedione, it should be viewed as a sentinel event indicating that there was a breakdown in exposure controls and that there is potential risk for co-workers. Should this occur, the unanticipated source of exposure must be identified and brought under control. In addition, increased intensity of medical surveillance would be required for all employees performing similar job tasks or having similar or greater potential for exposure. The NIOSH Criteria Document provides detailed guidance on responses to such sentinel events [NIOSH 2016].

\section{Smoking Cessation Program}

In a workplace with risk of occupational lung disease, prevention of smoking-related lung disease is important and makes the detection of work-related adverse effects easier. We 
recommend implementing a smoking cessation program to assist employees to stop smoking. The Centers for Disease Control and Prevention offers tools and resources for setting up a smoking cessation program [CDC 2018]. 


\section{Appendix A: Tables}

Table A1. OSHA Methods 1013/1016 full-shift personal and area air sampling results by location,

NIOSH industrial hygiene survey, May 2017.

\begin{tabular}{|c|c|c|c|c|c|c|c|c|}
\hline Analyte & $\begin{array}{c}\text { Sample } \\
\text { Type }\end{array}$ & $\begin{array}{c}\text { Work } \\
\text { Location }\end{array}$ & Location & $\mathbf{N}$ & $\begin{array}{c}\text { Above } \\
\text { LOD N } \\
(\%)\end{array}$ & $\begin{array}{c}\text { Minimum } \\
\text { Concentration } \\
\text { (ppb) }\end{array}$ & $\begin{array}{c}\text { Maximum } \\
\text { Concentration } \\
(\mathbf{p p b})\end{array}$ & $\begin{array}{c}\text { Above } \\
\text { REL N } \\
(\%)\end{array}$ \\
\hline Diacetyl & Personal & Uptown & Café & 4 & $4(100 \%)$ & 5.1 & 5.8 & $4(100 \%)$ \\
\hline Diacetyl & Personal & Roastery & Packaging & 1 & $1(100 \%)$ & 2.1 & 2.1 & $0(0 \%)$ \\
\hline Diacetyl & Personal & Roastery & Production Area & 2 & $2(100 \%)$ & 0.7 & 1.7 & $0(0 \%)$ \\
\hline Diacetyl & Personal & Roastery & Roasting & 1 & $1(100 \%)$ & 0.8 & 0.8 & $0(0 \%)$ \\
\hline Diacetyl & Personal & Downtown & Café & 5 & $5(100 \%)$ & 3.3 & 13.9 & $1(20 \%)$ \\
\hline Diacetyl & Area & Uptown & Café & 9 & $9(100 \%)$ & 2.4 & 7.6 & N/A \\
\hline Diacetyl & Area & Uptown & Outside & 3 & $1(33 \%)$ & $<0.3$ & 0.4 & N/A \\
\hline Diacetyl & Area & Roastery & Outside & 2 & $0(0 \%)$ & $<0.3$ & $<0.4$ & N/A \\
\hline Diacetyl & Area & Roastery & Production Area & 6 & $6(100 \%)$ & 0.4 & 1.0 & N/A \\
\hline Diacetyl & Area & Roastery & Roasting & 2 & $2(100 \%)$ & 0.7 & 0.8 & N/A \\
\hline Diacetyl & Area & Downtown & Café & 12 & $12(100 \%)$ & 3.2 & 5.5 & N/A \\
\hline Diacetyl & Area & Downtown & Outside & 3 & $0(0 \%)$ & $<0.3$ & $<0.3$ & N/A \\
\hline 2,3-Pentanedione & Personal & Uptown & Café & 4 & $4(100 \%)$ & 6.0 & 6.7 & $0(0 \%)$ \\
\hline 2,3-Pentanedione & Personal & Roastery & Packaging & 1 & $1(100 \%)$ & 1.3 & 1.3 & $0(0 \%)$ \\
\hline 2,3-Pentanedione & Personal & Roastery & Production Area & 2 & $2(100 \%)$ & 0.5 & 1.5 & $0(0 \%)$ \\
\hline 2,3-Pentanedione & Personal & Roastery & Roasting & 1 & $0(0 \%)$ & $<0.5$ & $<0.5$ & $0(0 \%)$ \\
\hline 2,3-Pentanedione & Personal & Downtown & Café & 5 & $5(100 \%)$ & 3.5 & 15.6 & $1(20 \%)$ \\
\hline 2,3-Pentanedione & Area & Uptown & Café & 9 & $9(100 \%)$ & 2.8 & 9.0 & N/A \\
\hline 2,3-Pentanedione & Area & Uptown & Outside & 3 & $1(33 \%)$ & $<0.3$ & 0.5 & N/A \\
\hline 2,3-Pentanedione & Area & Roastery & Outside & 2 & $0(0 \%)$ & $<0.3$ & $<0.4$ & N/A \\
\hline 2,3-Pentanedione & Area & Roastery & Production Area & 6 & $3(50 \%)$ & $<0.3$ & 0.6 & $\mathrm{~N} / \mathrm{A}$ \\
\hline 2,3-Pentanedione & Area & Roastery & Roasting & 2 & $1(50 \%)$ & $<0.4$ & 0.4 & $\mathrm{~N} / \mathrm{A}$ \\
\hline 2,3-Pentanedione & Area & Downtown & Café & 12 & $12(100 \%)$ & 3.2 & 6.5 & N/A \\
\hline 2,3-Pentanedione & Area & Downtown & Outside & 3 & $0(0 \%)$ & $<0.3$ & $<0.3$ & N/A \\
\hline 2,3-Hexanedione & Personal & Uptown & Café & 4 & $0(0 \%)$ & $<0.4$ & $<0.5$ & - \\
\hline 2,3-Hexanedione & Personal & Roastery & Packaging & 1 & $0(0 \%)$ & $<0.5$ & $<0.5$ & - \\
\hline 2,3-Hexanedione & Personal & Roastery & Production Area & 2 & $0(0 \%)$ & $<0.6$ & $<0.6$ & - \\
\hline 2,3-Hexanedione & Personal & Roastery & Roasting & 1 & $0(0 \%)$ & $<0.8$ & $<0.8$ & - \\
\hline 2,3-Hexanedione & Personal & Downtown & Café & 5 & $0(0 \%)$ & $<0.5$ & $<0.5$ & - \\
\hline 2,3-Hexanedione & Area & Uptown & Café & 9 & $0(0 \%)$ & $<0.5$ & $<0.5$ & N/A \\
\hline 2,3-Hexanedione & Area & Uptown & Outside & 3 & $0(0 \%)$ & $<0.5$ & $<0.5$ & $\mathrm{~N} / \mathrm{A}$ \\
\hline 2,3-Hexanedione & Area & Roastery & Outside & 2 & $0(0 \%)$ & $<0.5$ & $<0.6$ & N/A \\
\hline 2,3-Hexanedione & Area & Roastery & Production Area & 6 & $0(0 \%)$ & $<0.4$ & $<0.6$ & $\mathrm{~N} / \mathrm{A}$ \\
\hline 2,3-Hexanedione & Area & Roastery & Roasting & 2 & $0(0 \%)$ & $<0.5$ & $<0.6$ & $\mathrm{~N} / \mathrm{A}$ \\
\hline 2,3-Hexanedione & Area & Downtown & Café & 12 & $0(0 \%)$ & $<0.5$ & $<0.5$ & N/A \\
\hline 2,3-Hexanedione & Area & Downtown & Outside & 3 & $0(0 \%)$ & $<0.5$ & $<0.5$ & N/A \\
\hline
\end{tabular}

Note: $N=$ number of samples; Above LOD N (\%)=number and percentage of samples above limit of detection (LOD); < indicates below the LOD;

$<=$ indicates less than or equal to the LOD; Above REL N=number of samples above the NIOSH recommended exposure limit (REL); ppb=parts

per billion; N/A indicates that NIOSH RELs are specified for personal air samples, and cannot be used for direct comparisons with area samples; "-" indicates that there is currently no REL for 2,3-hexanedione. 


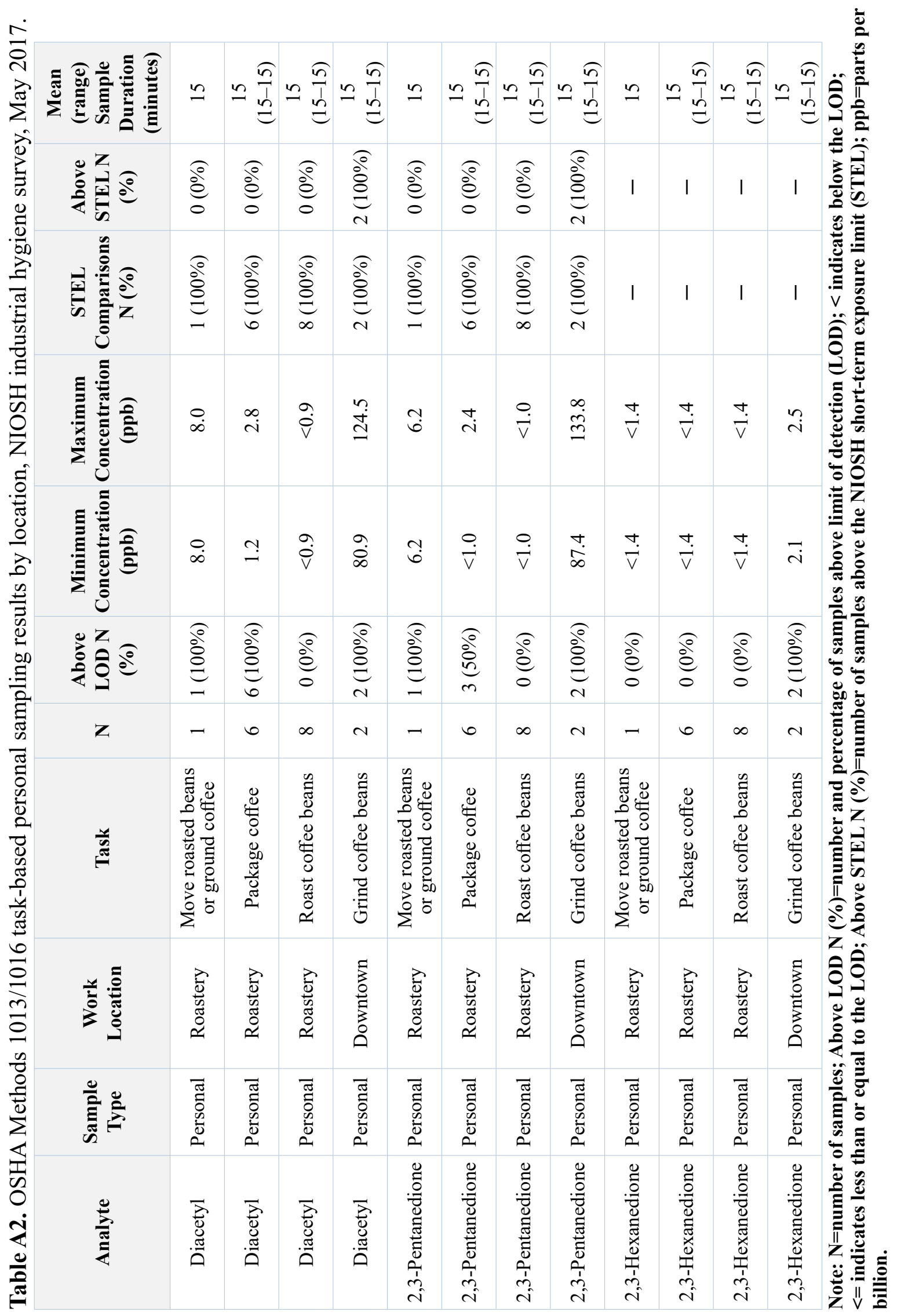




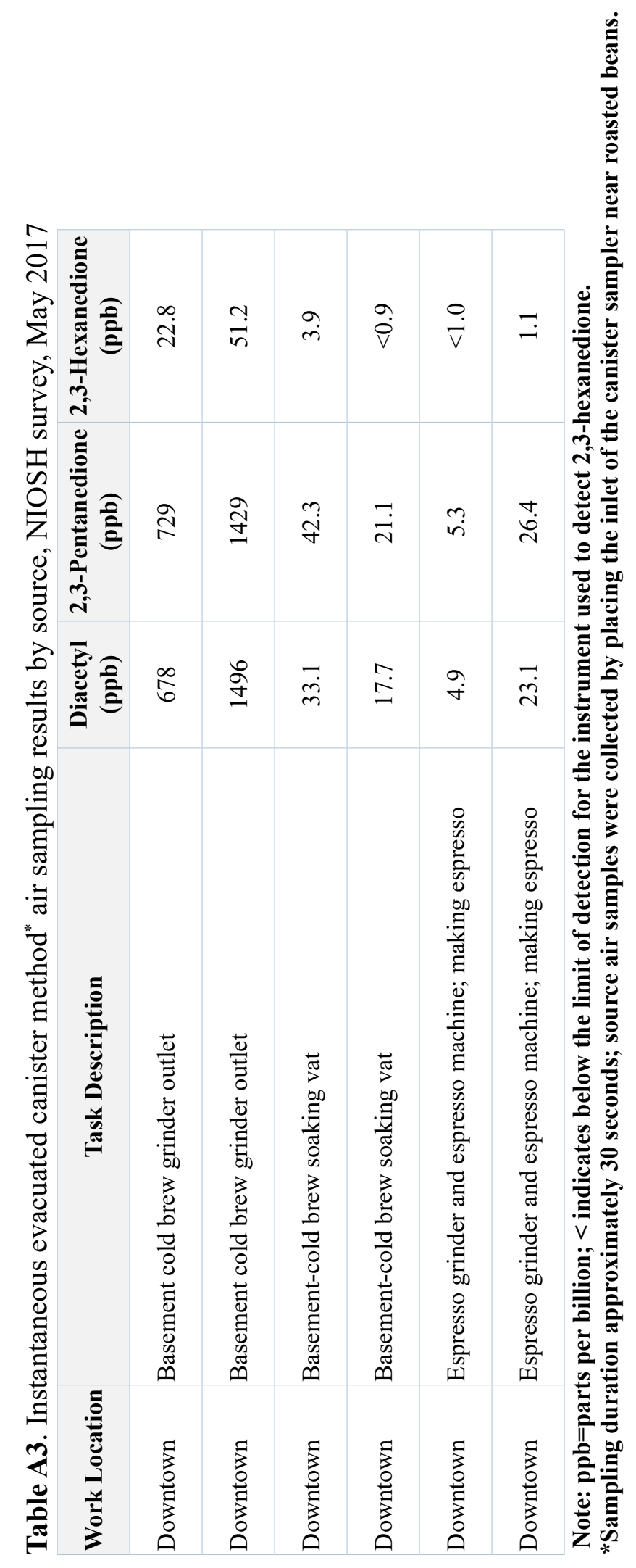

Health Hazard Evaluation Report 2016-0109-3343 


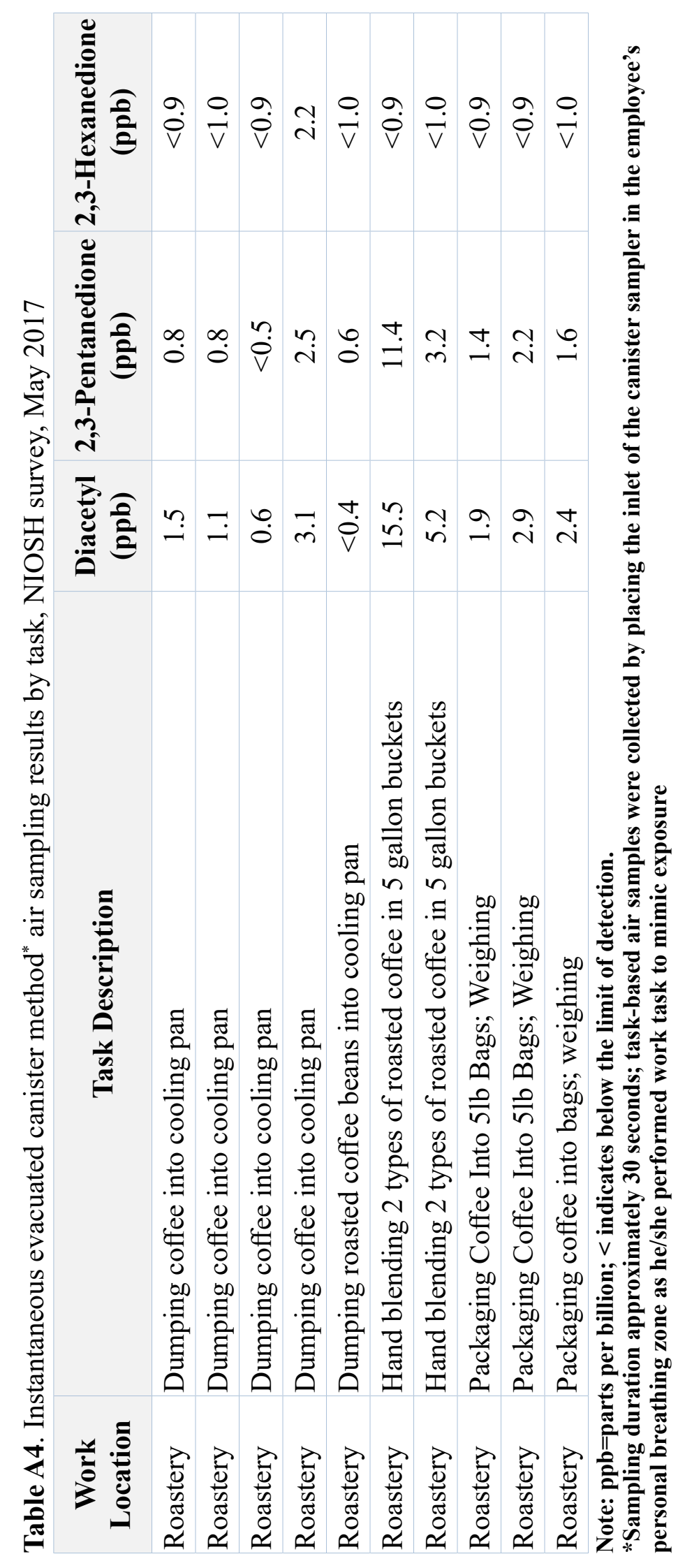




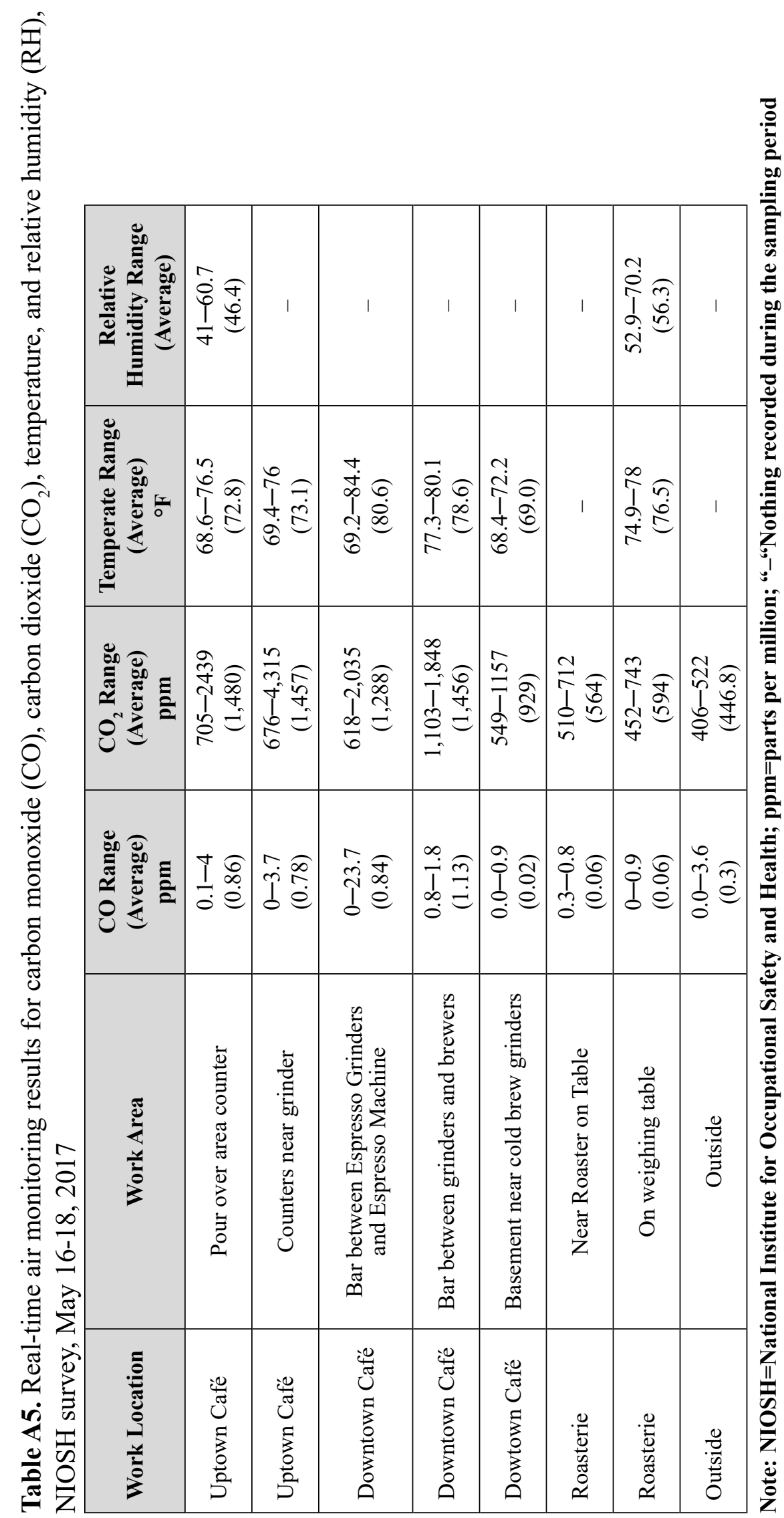




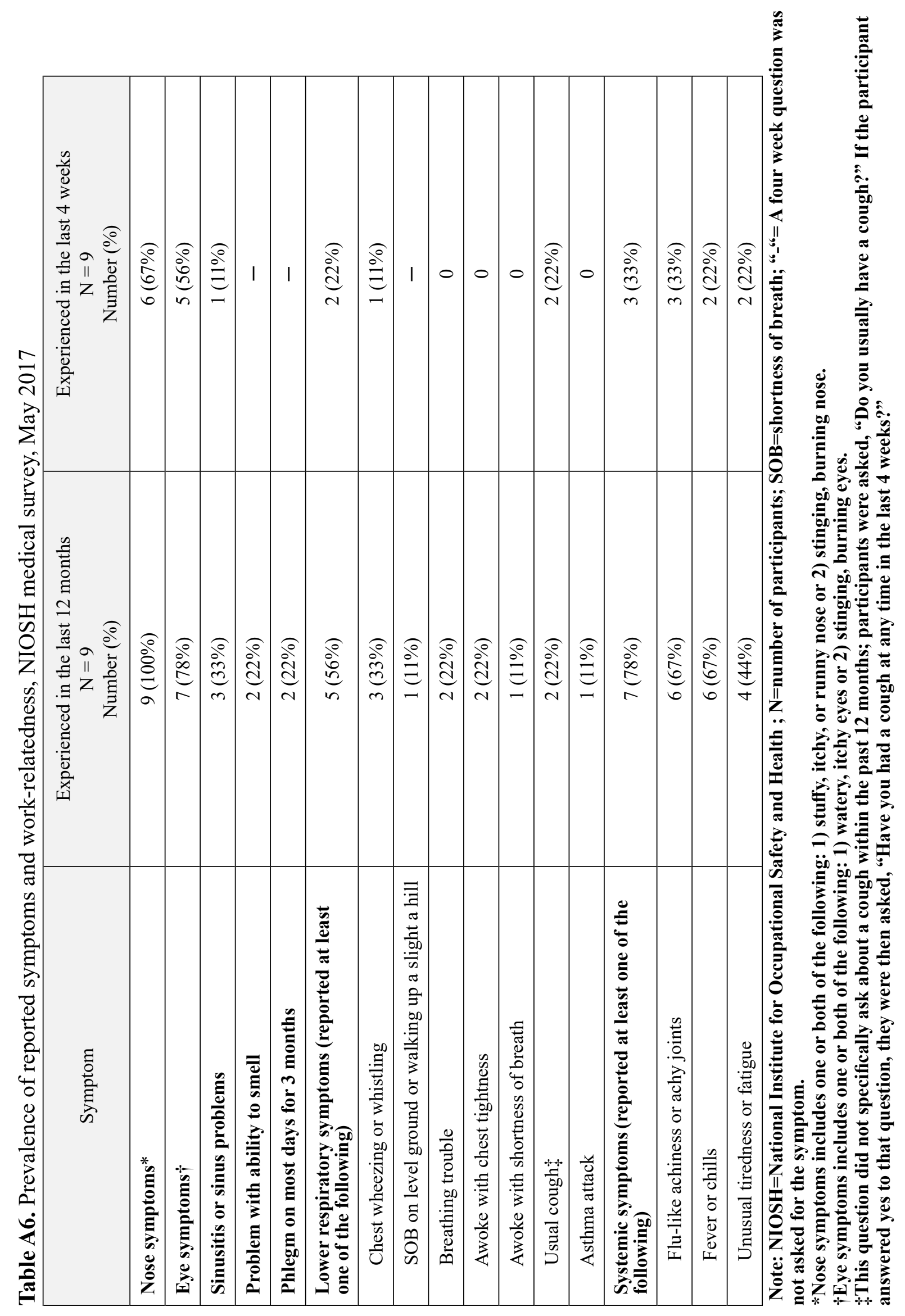


Table A7. Adjusted* comparisons of symptoms and self-reported physician diagnosis among NIOSH medical survey participants $(\mathrm{N}=9)$ to U.S. adult population, May 2017

\begin{tabular}{|l|l|c|c|c|}
\hline Health condition & Comparative population $\dagger$ & $\begin{array}{c}\text { Observed } \\
\text { Number }\end{array}$ & $\begin{array}{c}\text { Expected } \\
\text { Number }\end{array}$ & $\begin{array}{c}\text { SMR } \\
(95 \% \text { CI })^{\ddagger}\end{array}$ \\
\hline Watery, itchy eyes last 12 months & NHANES III & 7 & 3.8 & $1.8(0.9-3.8)$ \\
\hline Stuffy, itchy, or runny nose last 12 months & NHANES III & 9 & 5.6 & $1.6(0.8-3.0)$ \\
\hline Sinus problems last 12 months & NHANES III & 3 & 3.2 & $0.9(0.3-2.7)$ \\
\hline Phlegm 3 consecutive month or more & NHANES III & 2 & 0.6 & $3.4(0.9-12.6)$ \\
\hline Wheeze last 12 months & NHANES 2007-2012 & 3 & 1.4 & $2.1(0.7-6.1)$ \\
\hline Shortness of breath on exertion & NHANES III & 1 & 1.1 & $0.9(0.1-4.9)$ \\
\hline Ever asthma (physician-diagnosed) $)^{\S}$ & NHANES 2007-2012 & 2 & 0.6 & $3.2(0.9-11.5)$ \\
\hline Current asthma (physician-diagnosed) $)^{\S}$ & NHANES 2007-2012 & 1 & 0.4 & $2.7(0.5-15.3)$ \\
\hline
\end{tabular}

Note: NHANES=National Health and Nutrition Examination Survey; SMR= standardized morbidity ratio.

*Adjusted for sex, race/ethnicity, age, and smoking categories.

$\dagger$ We used the most recent NHANES survey available for each comparison.

$\$ 95 \%$ confidence intervals (CIs) that exclude one are statistically significantly different from comparison with US adult population and are shown in bold

§Participants with a history of asthma reported being diagnosed prior to employment at the coffee roasting and packaging facility and cafés. 


\section{References}

ACGIH (American Conference of Governmental Industrial Hygienists) [2018a]. 2017 TLVs ${ }^{\circledR}$ and BEIs ${ }^{\circledR}$ : Threshold limit values for chemical substances and physical agents and biological exposure indices. Cincinnati, $\mathrm{OH}$ : American Conference of Governmental Industrial Hygienists.

ACGIH [2018b]. Chemicals substances and other issues under study (TLV $\left.{ }^{\circledR}-\mathrm{CS}\right)$. [http:// www.acgih.org/tlv-bei-guidelines/documentation-publications-and-data/under-study-list/ chemical-substances-and-other-issues-under-study-tlv] Date accessed: March 2019.

Akiyama M, Murakami K, Ohtani N, Iwatsuki K, Sotoyama K, Wada A, Tokuno K, Iwabuchi $\mathrm{H}$, Tanaka K [2003]. Analysis of volatile compounds released during the grinding of roasted coffee beans using solid-phase microextraction. J Agric Food Chem 51(7):1961-1969.

Akpinar-Elci M, Travis WD, Lynch DA, Kreiss K [2004]. Bronchiolitis obliterans syndrome in popcorn production plant workers. Eur Respir J 24(2):298-302.

Anderson BA, Shimoni E, Liardon R, Labuza P [2003]. The diffusion kinetics of carbon dioxide in fresh roasted and ground coffee. J Food Eng 59:71-78.

ANSI (American National Standards Institute)/ASHRAE [2016]. Ventilation for acceptable indoor air quality, standard 62.1-2016. Atlanta, GA: ASHRAE.

Bailey RL, Cox-Ganser JM, Duling MG, LeBouf RF, Martin SB Jr, Bledsoe TA, Green BJ, Kreiss K [2015]. Respiratory morbidity in a coffee processing workplace with sentinel obliterative bronchiolitis cases. Am J Ind Med 58(12):1235-1245.

Berger KI, Reibman J, Oppenheimer BW, Vlahos I, Harrison D, Goldring RM [2013]. Lessons from the World Trade Center disaster: airway disease presenting as restrictive dysfunction. Chest 144(1):249-257.

Burney P, Chinn S [1987]. Developing a new questionnaire for measuring the prevalence and distribution of asthma. Chest 91(6 Suppl):79S-83S.

Burney PG, Laitinen LA, Perdrizet S, Huckauf H, Tattersfield AE, Chinn S, Poisson N, Heeren A, Britton JR, Jones T [1989]. Validity and repeatability of the IUATLD (1984) Bronchial symptoms questionnaire: an international comparison. Eur Respir J 2(10):940-945.

Burney PG, Luczynska C, Chinn S, Jarvis D [1994]. The European community respiratory health survey. Eur Respir J 7(5):954-960. 
CDC (Centers for Disease Control and Prevention) [1996]. Third National Health and Nutrition Examination Survey, 1988-1994, NHANES III Examination Data File [CDROM]. Hyattsville, Maryland: U.S. Department of Health and Human Services, Centers for Disease Control and Prevention. (Public use data file documentation No. 76300.)

CDC [2013a]. Carbon monoxide [https://www.cdc.gov/niosh/topics/co-comp/default.html]. Date accessed: March 2019.

CDC [2013b]. Obliterative bronchiolitis in workers in a coffee-processing facility-Texas, 2008-2012. Morb Mortal Wkly Rep 62(16):305-307.

CDC [2018]. Smoking \& tobacco use: quit smoking [https://www.cdc.gov/tobacco/stateandcommunity/tobacco control_programs/index.htm]. Date accessed: March 2019.

CFR. Code of Federal Regulations. Washington, DC: U.S. Government Printing Office, Office of the Federal Register.

Daglia M, Papetti A, Aceti C, Sordelli B, Spini V, Gazzani G [2007]. Isolation and determination of $\alpha$-dicarbonyl compounds by RP-HPLC-DAD in green and roasted coffee. $\mathrm{J}$ Agric and Food Chem 55(22):8877-8882.

Day G, LeBouf R, Grote A, Pendergrass S, Cummings K, Kreiss K, and Kullman G [2011]. Identification and measurement of diacetyl substitutes in dry bakery mix production. J Occ Env Hygiene 8(2):93-103.

de Assumpção MS, Gonçalves RM, Martins R, Bobbio TG, Schivinski CI [2016]. Reference equations for impulse oscillometry system parameters in healthy Brazilian children and adolescents. Respir Care 61(8):1090-1099.

Desiraju K, Agrawal A [2016]. Impulse oscillometry: The state-of-art for lung function testing. Lung India 33(4):410-416.

Duling MG, LeBouf RF, Cox-Ganser JM, Kreiss K, Martin SB Jr, Bailey RL [2016]. Environmental characterization of a coffee processing workplace with obliterative bronchiolitis in former workers. J Occup Environ Hyg 13(10):770-781.

Dweik RA, Boggs PB, Erzurum SC, Irvin CG, Leigh MW, Lundberg JO, Olin AC, Plummer AL, Taylor DR; American Thoracic Society Committee on Interpretation of Exhaled Nitric Oxide Levels (FENO) for Clinical Applications [2011]. An official ATS clinical practice guideline: interpretation of exhaled nitric oxide levels (FENO) for clinical applications. Am J Respir Crit Care Med 184(5):602-615.

ECRHS (European Community Respiratory Health Survey) [2014]. Questionnaires, protocols and instructions [http://www.ecrhs.org/Quests.htm]. Date accessed: March 2019. 
EAACI Task Force on Occupational Rhinitis, Moscato G, Vandenplas O, Gerth Van Wijk R, Malo JL, Quirce S, Walusiak J, Castano R, De Groot H, Folletti I, Gautrin D, Yacoub MR, Perfetti L, Siracusa A [2008]. Occupational rhinitis. Allergy 63(8):969-980.

Ferris BG [1978]. Epidemiology standardization project. Am Rev Respir Dis 118(Suppl):1-53.

Figley KD, Rawling FF [1950] Castor bean: an industrial hazard as a contaminant of green coffee dust and used burlap bags. J Allergy 21:545-553.

Hankinson JL, Odencrantz JR, Fedan KB [1999]. Spirometric reference values from a sample of the general U.S. population. Am J Respir Crit Care Med 159(1):179-187.

Hawley B, Cox-Ganser JM, Cummings KJ [2017] Carbon monoxide exposure in workplaces, including coffee processing facilities. Am J Respir Crit Care Med 196(8):1080-1081.

Henneberger PK, Redlich CA, Callahan DB, Harber P, Lemière C, Martin J, Tarlo SM, Vandenplas O, Torén K; ATS Ad Hoc Committee on Work-Exacerbated Asthma [2011]. An official American Thoracic Society statement: work-exacerbated asthma. Am J Respir Crit Care Med 184(3):368-378.

Hubbs AF, Cumpston AM, Goldsmith WT, Battelli LA, Kashon ML, Jackson MC, Frazer DG, Fedan JS, Goravanahally MP, Castranova V, Kreiss K, Willard PA, Friend S, SchweglerBerry D, Fluharty KL, Sriram K [2012]. Respiratory and olfactory cytotoxicity of inhaled 2,3-pentanedione in Sprague-Dawley rats. Am J Pathol 181(3):829-844.

Kanwal R, Kullman G, Piacitelli C, Boylstein R, Sahakian N, Martin S, Fedan K, Kreiss K [2006]. Evaluation of flavorings-related lung disease risk at six microwave popcorn plants. J Occup Environ Med. 48(2):149-57.

Karr RM, Davies RJ, Butcher BT, Lehrer SB, Wilson MR, Dharmarajan V, Salvaggio JE [1978]. Occupational asthma. J Allergy Clin Immunol 61(1):54-65.

Kim TJ, Materna BL, Prudhomme JC, Fedan KB, Enright PL, Sahakian NM, Windham GC, Kreiss K [2010]. Industry-wide medical surveillance of California flavor manufacturing workers: Cross-sectional results. Am J Ind Med 53(9):857-865.

King MS, Eisenberg R, Newman JH, Tolle JJ, Harrell FE Jr, Nian H, Ninan M, Lambright ES, Sheller JR, Johnson JE, Miller RF [2011]. Constrictive bronchiolitis in soldiers returning from Iraq and Afghanistan. N Engl J Med. 365(3):222-230.

Kreiss K [2013]. Occupational causes of constrictive bronchiolitis. Curr Opin Allergy Clin Immunol 13(2):167-172. 
Komarow HD, Myles IA, Uzzaman A, Metcalfe DD [2011]. Impulse oscillometry in the evaluation of diseases of the airways in children. Ann Allergy Asthma Immunol 106(3):191199.

Langford NJ [2005]. Carbon dioxide poisoning. Toxicol Rev 24(4):229-235.

LeBouf RF and Simmons M [2017]. Increased sensitivity of OSHA method analysis of diacetyl and 2,3-pentanedione in air. J Occup Environ Hyg 14(5):343-348.

Lee JY, Seo JH, Kim HY, Jung YH, Kwon JW, Kim BJ, Kim HB, Lee SY, Jang GC, Song DJ, Kim WK, Shim JY, Kim HJ, Shin YJ, Park JW, Cho SH, Lee JS, Hong SJ [2012]. Reference values of impulse oscillometry and its utility in the diagnosis of asthma in young Korean children. J Asthma 49(8):811-816.

Lehrer SB, Karr RM, Salvaggio JE [1978]. Extraction and analysis of coffee bean allergens. Clin Allergy 8(3):217-226.

Malmberg LP, Pelkonen A, Poussa T, Pohianpalo A, Haahtela T, Turpeinen M [2002]. Determinants of respiratory system input impedance and bronchodilator response in healthy Finnish preschool children. Clin Physiol Funct Imaging 22(1):64-71.

Miller MR, Hankinson J, Brusasco V, Burgos F, Casaburi R, Coates A, Crapo R, Enright P, van der Grinten CP, Gustafsson P, Jensen R, Johnson DC, MacIntyre N, McKay R, Navajas D, Pedersen OF, Pellegrino R, Viegi G, Wanger J, ATS/ERS Task Force [2005]. Standardisation of spirometry. Eur Respir J 26(2):319-338.

Morgan DL, Jokinen MP, Price HC, Gwinn WM, Palmer SM, Flake GP [2012]. Bronchial and bronchiolar fibrosis in rats exposed to 2,3-pentanedione vapors: implications for bronchiolitis obliterans in humans. Toxicol Pathol 40(3):448-465.

Morgan DL, Jokinen MP, Johnson CL, Price HC, Gwinn WM, Bousquet RW, Flake GP [2016]. Chemical reactivity and respiratory toxicity of the $\alpha$-diketone flavoring agents: 2,3-butanedione, 2,3-pentanedione, and 2,3-hexanedione. Toxicol Pathol 44(5):763-783.

NCHS (National Center for Health Statistics) [2015]. National Health and Nutrition Examination Survey (NHANES). Hyattsville, Maryland: U.S. Department of Health and Human Services, Centers for Disease Control and Prevention. [http://www.cdc.gov/nchs/ nhanes/about_nhanes.htm]. Date assessed: March 2019.

Newbury W, Crockett A, Newbury J [2008]. A pilot study to evaluate Australian predictive equations for the impulse oscillometry system. Respirology 13(7):1070-1075.

Newton J [2002]. Carbon monoxide exposure from coffee roasting. Appl Occup Environ Hyg. 17(9):600-602. 
NIOSH (2004). NIOSH respirator selection logic. Department of Health and Human Services, Centers for Disease Control and Prevention, National Institute for Occupational Safety and Health DHHS (NIOSH) Publication No. 2005-100 [https:/www.cdc.gov/niosh/ docs/2005-100/pdfs/2005-100.pdf]. Date accessed: March 2019.

NIOSH [2010]. NIOSH pocket guide to chemical hazards. Cincinnati, OH: U.S. Department of Health and Human Services, Centers for Disease Control and Prevention, National Institute for Occupational Safety and Health, DHHS (NIOSH) Publication No. 2010-168c [http://www.cdc.gov/niosh/npg/]. Date accessed: March 2019.

NIOSH [2012]. Flavoring-related lung disease. Information for healthcare providers. Department of Health and Human Services, Centers for Disease Control and Prevention, DHHS (NIOSH) Publication No. 2012-148 (supersedes 2012-107) [http://www.cdc.gov/ niosh/docs/2012-148/]. Date accessed: March 2019.

NIOSH [2016]. Criteria for a recommended standard: occupational exposure to diacetyl and 2,3-pentanedione. U.S. Department of Health and Human Services, Centers for Disease Control and Prevention, National Institute for Occupational Safety and Health, DHHS (NIOSH) Publication No. 2016-111. [https://www.cdc.gov/niosh/docs/2016-111/]. Date accessed: March 2019.

NIOSH [2018a]. Work-related asthma [https:/www.cdc.gov/niosh/topics/asthma/default. html]. Date accessed: March 2019.

NIOSH [2018b]. Volatile organic compounds, C1 to C10, Canister method: Method 3900. In Ashley K, O’Connor PF, eds. NIOSH manual of analytical methods (NMAM $\left.{ }^{\circledR}\right) .5^{\text {th }}$ ed. [https://www.cdc.gov/niosh/nmam/pdf/3900.pdf]. Date accessed: March 2019.

Nishimura F, Abe S, Fukunaga T [2003]. Carbon monoxide poisoning from industrial coffee extraction. JAMA 290(3):334.

Oldenburg M, Bittner C, Baur X [2009]. Health risks due to coffee dust. Chest 136(2):536544.

Oppenheimer BW, Goldring RM, Herberg ME, Hofer IS, Reyfman PA, Liautaud S, Rom WN, Reibman J, Berger KI [2007]. Distal airway function in symptomatic subjects with normal spirometry following World Trade Center dust exposure. Chest 132(4):1275-1282.

OSHA (Occupational Safety and Health Administration) [1993]. Compliance and enforcement activities affected by the PELs decision. August 5, 1993 Memorandum. [https:// www.osha.gov/pls/oshaweb/owadisp.show document?p table=INTERPRETATIONS\&p

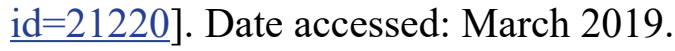


OSHA [2003]. Enforcement policy for respiratory hazards not covered by OSHA permissible exposure limits. January 24, 2003 Memorandum. [https://www.osha.gov/pls/oshaweb/ owadisp.show document?p table=INTERPRETATIONS\&p id=24749]. Date accessed: March 2019.

OSHA [2008]. Sampling and analytical methods: Method 1013 - Acetoin and diacetyl [http:// www.osha.gov/dts/sltc/methods/validated/1013/1013.html]. Date accessed: March 2019.

OSHA [2010]. Sampling and analytical methods: Method 1016 - 2,3-pentanedione [http:// www.osha.gov/dts/sltc/methods/validated/1016/1016.html]. Date accessed: March 2019.

OSHA [2014]. OSHA Fact sheet: Do you have work-related asthma? A guide for you and your doctor. Washington, D.C.: U.S. Department of Labor, Occupational Safety and Health Administration [https://www.osha.gov/Publications/OSHA3707.pdf]. Date accessed: March 2019.

OSHA [2016]. Permissible exposure limits - annotated tables [https://www.osha.gov/dsg/annotated-pels/index.html]. Date accessed: March 2019.

Park JH, Yoon JW, Shin YH, Jee HM, Wee YS, Chang SJ, Sim JH, Yum HY, Han MY [2011]. Reference values for respiratory system impedence using impulse oscillometry in healthy preschool children. Korean J Pediatr 54(2)64-68.

Pellegrino R, Viegi G, Brusasco V, Crapo RO, Burgos F, Casaburi R, Coates A, van der Grinten CP, Gustafsson P, Hankinson J, Jensen R, Johnson DC, MacIntyre N, McKay R, Miller MR, Navajas D, Pedersen OF, Wanger J [2005]. Interpretative strategies for lung function tests. Eur Respir J 26(5):948-968.

Raffel JB, Thompson J [2013]. Carbon monoxide from domestic coffee roasting: a case report. Ann Intern Med 159(11):795-796.

Rondón C, Campo P, Galindo L, Blanca-López N, Cassinello MS, Rodriguez-Bada JL, Torres MJ, Blanca M [2012]. Prevalence and clinical relevance of local allergic rhinitis. Allergy. 67(10):1282-1288.

Rondón C, Bogas G, Barrionuevo E, Blanca M, Torres MJ, Campo P [2017]. Nonallergic rhinitis and lower airway disease. Allergy 72(1):24-34.

Rose JJ, Wang L, Xu Q, McTiernan CF, Shiva S, Tejero J, Gladwin MT [2017]. Carbon monoxide poisoning: pathogenesis, management, and future directions of therapy. Am J Respir Crit Care Med 195(5):596-606.

Sahay S, Gera K, Bhargava SK, Shah A [2016]. Occurrence and impact of sinusitis in patients with asthma and/or allergic rhinitis. J Asthma 53(6):635-643. 
Sakwari G, Mamuya SH, Bråtveit M, Moen BE [2013]. Respiratory symptoms, exhaled nitric oxide, and lung function among workers in Tanzanian coffee factories. J Occup Environ Med 55(5):544-551.

Schulz H, Flexeder C, Behr J, Heier M, Holle R, Huber RM, Jörres RA, Nowak D, Peters A, Wichmann HE, Heinrich J, Karrasch S; KORA Study Group [2013]. Reference values of impulse oscillometric lung function indices in adults of advanced age. PLoS One 8(5):e63366. doi: 10.1371/journal.pone.0063366.

Schulze J, Biedebach S, Christmann M, Herrmann E, Voss S, Zielen S [2016]. Impulse oscillometry as a predictor of asthma exacerbations in young children. Respiration 91(2):107114.

Shaaban R, Zureik M, Soussan D, Neukirch C, Heinrich J, Sunyer J, Wjst M, Cerveri I, Pin I, Bousquet J, Jarvis D, Burney PG, Neukirch F, Leynaert B [2008]. Rhinitis and onset of asthma: a longitudinal population-based study. Lancet. 372(9643):1049-1057.

Shi Y, Aledia AS, Tatavoosian AV, Vijayalakshmi S, Galant SP, George SC [2012]. Relating small airways to asthma control by using impulse oscillometry in children.

Allergy Clin Immunol 129(3):671-678.

Smith HJ, Reinhold P, Goldman MD [2005]. Forced oscillation technique and impulse oscillometry. In: Gosselink R, Stam H, eds. European Respiratory Monograph 31: Lung Function Testing. Vol. 10. Wakefield, UK: European Respiratory Society Journals, pp. 72105.

Smith HJ (Hans-Juergen.Smith@CareFusion.com) [2015]. Questions about impulse oscillometry. Email of December 9, 2015, from Hans-Juergen Smith, CareFusion, to Rachel Bailey (feu2@cdc.gov), Respiratory Health Division, National Institute for Occupational Safety and Health, Centers for Disease Control and Prevention, Department of Health and Human Services.

Song TW, Kim KW, Kim ES, Park JW, Sohn MH, Kim KE [2008]. Utility of impulse oscillometry in young children with asthma. Pediatr Allergy Immunol 19(8):763-768.

Tarlo SM, Lemiere C [2014]. Occupational asthma. N Engl J Med 370:640-649.

Tarlo SM [2016]. Update on work-exacerbated asthma. Int J Occup Med Environ Health 29(3):369-374.

Thomas KE, Trigg CJ, Baxter PJ, Topping M, Lacey J, Crook B, Whitehead P, Bennett JB, Davies RJ [1991]. Factors relating to the development of respiratory symptoms in coffee process workers. Br J Ind Med 48(5):314-322. 
Vogel J, Smidt U [1994] Impulse oscillometry. Analysis of lung mechanics in general practice and clinic, epidemiological and experimental research. $1^{\text {st }}$ ed. Frankfurt: PMIVerlagsgruppe.

Weinstein DJ, Hull JE, Ritchie BL, Hayes JA, Morris MJ [2016]. Exercise-associated excessive dynamic airway collapse in military personnel. Ann Am Thorac Soc 13(9):14761482.

Zuskin E, Valić F, Skurić Z [1979]. Respiratory function in coffee workers. Br J Ind Med $36(2): 117-122$.

Zuskin E, Kanceljak B, Skurić Z, Butković D [1985]. Bronchial reactivity in green coffee exposure. Br J Ind Med 42(6):415-420.

Zuskin E, Schachter EN, Kanceljak B, Witek TJ Jr, Fein E [1993]. Organic dust disease of airways. Int Arch Occup Environ Health 65(2):135-140. 
This page left intentionally blank 
Keywords: NAICS 311920 (Coffee Roasting), Pennsylvania, diacetyl, 2,3-pentanedione, 2,3-hexanedione, coffee, carbon monoxide, carbon dioxide, volatile organic compounds (VOCs). 
The Health Hazard Evaluation Program investigates possible health hazards in the workplace under the authority of the Occupational Safety and Health Act of 1970 (29 U.S.C. $§ 669$ (a) (6)). The Health Hazard Evaluation Program also provides, upon request, technical assistance to federal, state, and local agencies to investigate occupational health hazards and to prevent occupational disease or injury. Regulations guiding the Program can be found in Title 42, Code of Federal Regulations, Part 85; Requests for Health Hazard Evaluations (42 CPR Part 85).

\section{Disclaimer}

The recommendations in this report are made on the basis of the findings at the workplace evaluated and may not be applicable to other workplaces.

Mention of any company or product in this report does not constitute endorsement by the National Institute for Occupational Safety and Health (NIOSH).

Citations to Web sites external to NIOSH do not constitute NIOSH endorsement of the sponsoring organizations or their programs or products. NIOSH is not responsible for the content of these Web sites. All Web addresses referenced in this document were accessible as of the publication date.

\section{Acknowledgments}

Desktop Publisher: Tia McClelland

Data Analysis Support: Nicole Edwards, Kathleen Fedan, and Brian Tift Laboratory Support: Dru Burns, Ryan LeBouf, Anand Ranpara, and Yeonmi Park Site Visit Team Members: Tia McClelland, Randy Boylstein, Stephen Martin, and Michael Beaty

\section{Availability of Report}

Copies of this report have been sent to the employer and employees at the facility. The state health department and the Occupational Safety and Health Administration Regional Office have also received a copy. This report is not copyrighted and may be freely reproduced.

This report is available at https://www.cdc.gov/niosh/hhe/reports/pdfs/2016-0109-3343.pdf.

All other Health Hazard Evaluation Reports may be found at https://www2a.cdc.gov/hhe/ search.asp.

\section{Recommended citation for this report:}

$\mathrm{NIOSH}$ [2019]. Health hazard evaluation report: Evaluation of exposure and respiratory health at a coffee roasting and packaging facility and two off-site retail cafés. By McClelland T, Boylstein RJ, Martin SB, Beaty M. Morgantown, WV: U.S. Department of Health and Human Services, Centers for Disease Control and Prevention, National Institute for Occupational Safety and Health, NIOSH HHE Report No. 2016-0109-3343. 
Delivering on the Nation's promise:

Safety and health at work for all people through research and prevention

To receive documents or other information about occupational safety and health topics, contact NIOSH

Telephone: 1-800-CDC-INFO (1-800-232-4636)

TTY: 1-888-232-6348

email: cdcinfo@cdc.gov

or visit the NIOSH website at http://www.cdc.gov/niosh

SAFER • HEALTHIER $\cdot$ PEOPLE $^{\text {TM }}$ 